Citation: Kenndler E. (2021) Tit Capillary Electrophoresis and its Basic Principles in Historical Retrospect. Part 2. Electrophoresis of lons: the Period from its Discovery in 1800 till Faraday's Lines of Electric Force in the 1840s. Substantia 5(2): 97-120. doi: 10.36253/Substantia-1312

Received: May 10, 2021

Revised: Jun 15, 2021

Just Accepted Online: Jun 16, 2021

Published: Sep 10, 2021

Copyright: (c) 2021 Kenndler E. This is an open access, peer-reviewed article published by Firenze University Press (http://www.fupress.com/substantia) and distributed under the terms of the Creative Commons Attribution License, which permits unrestricted use, distribution, and reproduction in any medium, provided the original author and source are credited.

Data Availability Statement: All relevant data are within the paper and its Supporting Information files.

Competing Interests: The Author(s) declare(s) no conflict of interest.
Historical Articles

\section{Capillary Electrophoresis and its Basic Principles in Historical Retrospect. Part 2. Electrophoresis of Ions: the Period from its Discovery in 1800 till Faraday's Lines of Electric Force in the 1840s.}

\author{
ERNST KenNDLER \\ Institute for Analytical Chemistry, Faculty of Chemistry, University of Vienna, Vienna, \\ Austria \\ E-mail: ernst.kenndler@univie.ac.at
}

\begin{abstract}
This review is the first in a series that deals exclusively with electrophoresis of ions. Since in modern terminology "electrophoresis is the movement of dispersed particles relative to a fluid under the influence of a spatially uniform electric field", electrophoresis is not limited to colloidal particles, it includes ions as well. The history of electrophoresis of ions therefore begins in 1800 at the same time as that of electrolysis, because the two phenomena are so inextricably linked "that one cannot happen without the other" (Faraday, 1834). Between 1800 and 1805 about half a dozen different theories of electrolytic decomposition and the movement of the particles - for which we coin the term electrophoretic current - were formulated, all contributing to the discourse, but lacking consistency and none fully convincing. They are discussed nonetheless because most of them fell into oblivion, even though they are interesting for historical reasons. However, from 1805/1806 the predominant theory, formulated by Theodor von Grotthuß and independently by Humphry Davy assumed that polarized molecules of water or dissolved ions form chains between the two electrodes. Only the terminal atoms of these chains were in direct contact with the electrodes and were liberated by galvanic action, but are immediately replaced by neighboring atoms of the same type. This decomposition and recombination of the molecules driven by electric forces which follow the "action at a distance" principle like in Coulomb's law takes place over the entire chains; they represent the electrophoretic current. However, in 1833 Michael Faraday refuted all previous theories. Two of his groundbreaking findings were of particular importance for the electrophoresis of ions: one was that electricity consists of elementary units of charge. The ions thus carry one or integer multiples of these units. The other was the revolutionary theory of the electric lines of force in early 1840s, and of what was later called the electric field. With these findings Faraday fundamentally changed the previously prevailing view of the electrophoresis of ions.
\end{abstract}

Keywords: Ion electrophoresis, history, action at a distance, lines of electric force. 


\section{INTRODUCTION}

While the discovery of three phenomena - electrolysis, electrophoresis of colloids and electroosmosis - was discussed in Part 1 of our historical review about capillary electrophoresis ${ }^{[1]}$ the present Part 2 will focus on the ensuing studies of the electrophoresis of ions, along with the inextricably linked electrolysis.

Historic sources reveal that electrophoresis was discovered by Nicolas Gautherot in $1801^{[2]}$ and independently by Ferdinand Friedrich von Reuß in 1807. $[3,4]$ However, both discoveries have in common that the experimenters observed the motion of colloids and coarse granular particles, dispersed in water, when the electrodes of a voltaic pile were dipped into the dispersion and the electric circuit was closed. The large size of the particles enabled the observation of the particle's movement by naked eye. Yet, this was one of the reasons why electrophoresis has been attributed to particles of this relatively large size over more than a century after its discovery. It is to note that IUPAC also shares this view and recommends that electrophoresis is "the motion of colloidal particles in an electric field". ${ }^{[5]}$ But this view fell short and was for good reasons expanded since nearly one century to ions, small charged particles of atomic or molecular size. At this point it is emphasized that colloids do not differ from ions only by their size, but also by their structure. ${ }^{1}$

Notwithstanding this difference, the updated and more generalized definition of electrophoresis currently agreed by the majority of the scientific community reads that "electrophoresis is the movement of dispersed particles relative to a fluid under the influence of a spatially uniform electric field". ${ }^{2}$ According to this definition, electrophoresis encompasses a general principle. ${ }^{3}$

\footnotetext{
${ }^{1}$ Electrophoresis of colloids, as well as electroosmosis, belong to the class of electrokinetic phenomena. Colloids, to be precise, colloidal particles, are an own phase in a second phase, they form heterogeneous dispersions, in which the two phases form an electric double layer at their interphase. Ions, in contrast, form homogeneous solution with the continuous medium in which they are dissolved.

${ }^{2}$ In our text, we usually added the adjective "charged" to the term "particle" as it facilitates its reading. However, this is not required and the adjective "charged" can be omitted. The reason is that an uncharged particle can move under the influence of a field by electroosmosis, but in this case it does not move relative to the fluid but just like the fluid. When the motion of an uncharged particle is caused by diffusion or convection, it does move relative to the fluid, but not caused by the electric field. Only a charged particle will definitely move in the field relative to the fluid due to the electrical force acting on it; therefore, the addition of the adjective is needless.

${ }^{3}$ We think that it is necessary to account for this wider view of electrophoresis, since it is at present mainly considered as a separation method only. In contrast, we endorse the above cited general definition (see. e.g. refs. ${ }^{[6]}$ and ${ }^{[7}$ ). It should be noted that this definition
}

With regard to this broader view at electrophoresis, reference is made to the more detailed discussion in Part 1 of this series.

Does this generalizing definition of electrophoresis lead to a dilemma concerning the date of its discovery? It was already inferred on the occasion of electrolysis in 1800 that dissolved ions migrate in their solutions under the influence of an electric field. This finding clearly corresponds to the criterion of electrophoresis. In contrast to colloids or coarse granular particles the motion of ions could not be directly followed visually due to their small size, but their migration and the direction in which they move had been proven indirectly from their concentrations close to the electrodes and their decomposition products which were formed by the simultaneous electrolysis process. Contemporary researchers therefore concluded that ions undoubtedly also move by what we call electrophoresis, at the same time when electrolysis occurs.

We therefore consider the commencement of electrophoresis, strictly speaking the electrophoresis of ions, to be the day when William Nicholson and Sir Antony Carlisle split water into gaseous hydrogen and oxygen by electrolysis $^{[8,9]}$ with the newly discovered galvanic electricity. ${ }^{4}$ For William Cruickshank the migration of the parts of the decomposable "body" and their perplexing occurrence at the separate poles was a "mysterious" phenomenon, for Humphry Davy "the agency of galvanism is at present involved in obscurity", and this unintelligible effect provoked an intense research of its causes.

The entire first series of our historical retrospect focuses exclusively on ions in solutions. This series about ions consists of this and of following articles and covers the period between 1800 and the end of the Long 19th Century in $1914,{ }^{5}$ or what we termed in Part 1 the $1 s t$

applies to all dispersed particles, from the smallest inorganic ions up to viruses, bacteria and cells. Moreover, in none of the definitions or recommendations electrophoresis is limited to separation methods. Note that neither Gautherot nor von Reuß, the classical discoverers of electrophoresis, carried out separations. So we find no sound reason not to base the view on electrophoresis on the general principle outlined above. In this sense electrophoresis is not a separation method, but can be utilized as such.

${ }^{4}$ We briefly mention that a different terminology was used in the original documents compared to the current ones. Even the term electrophoresis was unknown until the Short 20th Century. In the present article we use - ahistorically - the modern terminology, but occasionally also the contemporary one of the original works, for instance when we quote verbatim. "Pole", i.e., was substituted by "electrode" not until 1833.

${ }^{5}$ We borrowed the term Long 19th Century from Eric Hobsbawm's trilogy on European history between the French Revolution in 1879 and the begin of World War I in 1914. It is the same period of time, in which all the main principles and theories of electrophoresis were already known, but - surprisingly - no attempts were made in this " 1 st epoch" to use them for a separation method; see Part 1. ${ }^{[1]}$ 
epoch of electrophoresis. We repeat that the electrophoresis of colloidal particles is not included, since its history cannot be told without that of the ions. A historical retrospect of electrophoresis of colloids, together with that of electroosmosis, will be the topic of a future separate series of articles.

The narrative in the present Part 2 of this series about ions spans the period from the discovery of electrolysis in year 1800 to the 1840 s. In those 1840 s, Michael Faraday overthrew the hitherto established concept of the action at a distance by the introduction of the groundbreaking theory of the lines of electric force or lines of action (later called field lines of the electric field).

One would expect this Part 2 to continue with electrophoresis only. However, it is inevitable to consider that the theories of electrophoresis would have remained in the dark without the results obtained by electrolysis. Indeed, one can argue that the theories about electrophoresis had their roots in the conclusions drawn from the experimental results of electrolysis.

Before we begin the historical review of the development of electrophoresis, we would like to mention briefly that almost all technical terms, with the exception of galvanic electricity, which have been used so far in this text, were unknown at this point in time. Moreover, the term electrophoresis remained unknown even during the Long 19th Century. Still, we find it useful to coin a new term in the present part. Our motivation is that in the early literature the complete electrical current flowing during electrolysis was expressed by many different and ambiguous phrases such as "the flow ..., the transmittance ..., the transfer ..., the transmission of electricity, ... the transport of galvanic electricity" and several others. However, this complete current consists in two different forms. The galvanic current is the current of electrons in the metallic conductors of the circuit, and differs principally from the flow of charges which are carried by the dissolved ions. Hence, we think we have every reason to merge the various historical and confusing expressions for the flow of the charges by ions in solutions into the single and unambiguous term electrophoretic current.$^{6}$ This term is not usual, but it is to the point, and is full in line with the definition of electrophoresis.

\footnotetext{
${ }^{6}$ We coin the term electrophoretic current analogue to the term galvanic current. We mention, however, that we are not consistently replacing the various terms used at that time by electrophoretic current. We replace them when it is appropriate in the context.
}

\section{HOW DOES ELECTRICITY FLOW THROUGH WATER OR THROUGH SOLUTIONS OF COMPOUNDS DISSOLVED THEREIN DURING THEIR DECOMPOSITION?}

In the beginning of research in the effect of galvanic electricity on water ${ }^{7}$ and its electrolyte solutions, researchers in Britain dominated this area for the first two years after its discovery. Admittedly, their investigations were rather directed on the chemical transformation of the constituents of the liquid at the electrodes by electrolysis than on the flow of the electric current through the liquid. Their findings were published mainly in Nicholson's Journal, ${ }^{8}$ which served them as a kind of "Central Organ". This can be said considering the remarkable large number of the appropriate papers in Volume IV from 1801, which was the first to publish articles on this subject. The title page of this volume of historic merit is shown in Figure 1.

It was the volume where William Nicholson reported the discovery of the decomposition of water by galvanic electricity. ${ }^{[9]}$ In addition, in the same volume William Cruickshank proposed a first theory of electrolysis and please note - the inextricable linked transport of electrified particles of atomic size in solution between the poles. ${ }^{[1]}$

\subsection{September 1800: The first theories by William Cruick- shank and by Johann Wilhelm Ritter}

2.1.1 W. Cruickshank's theory of the oxygenated and the deoxygenated electric fluid

William Cruickshank, a friend of Nicholson, ${ }^{9}$ was the first who reported his investigations on the present

\footnotetext{
${ }^{7}$ It is important to realize that through the period under consideration water that was used for the experiments was never pure, but was always contaminated with impurities. Even when it was distilled, it certainly contained electrolytes. Water with highest purity was first obtained around 1890 by Adolf Heydweiller, a coworker of Friedrich Kohlrausch, after fiftyfold distillation under vacuum in a quartz apparatus. We mention this fact because the detailed process of the electrolytic decomposition of water depends on its purity, and on the kind of the contaminants or on the intentionally added compounds such as acids, bases or salts. Acidulation, for instance, increases the speed of the generation of the gases. In this context, Faraday stated in 1834 that "even water itself, which so easily yields up its elements when the current passes, if rendered quite pure, scarcely suffers change, because it then becomes a very bad conductor". ${ }^{[10]}$

${ }^{8}$ This periodical journal was founded in 1797 and published by William Nicholson entitled Journal of Natural Philosophy, Chemistry \& the Arts. It was commonly called Nicholson's Journal, and merged in 1814 with the Philosophical Magazine to The Philosophical Magazine and Journal, later named The Philosophical Magazine. Please note the combination of natural philosophy, chemistry and arts at the time.

${ }^{9}$ There is not a very detailed record of William Cruickshank's life. He
} was born in north-east Scotland in the 1740s or 1750s. Known is that in 


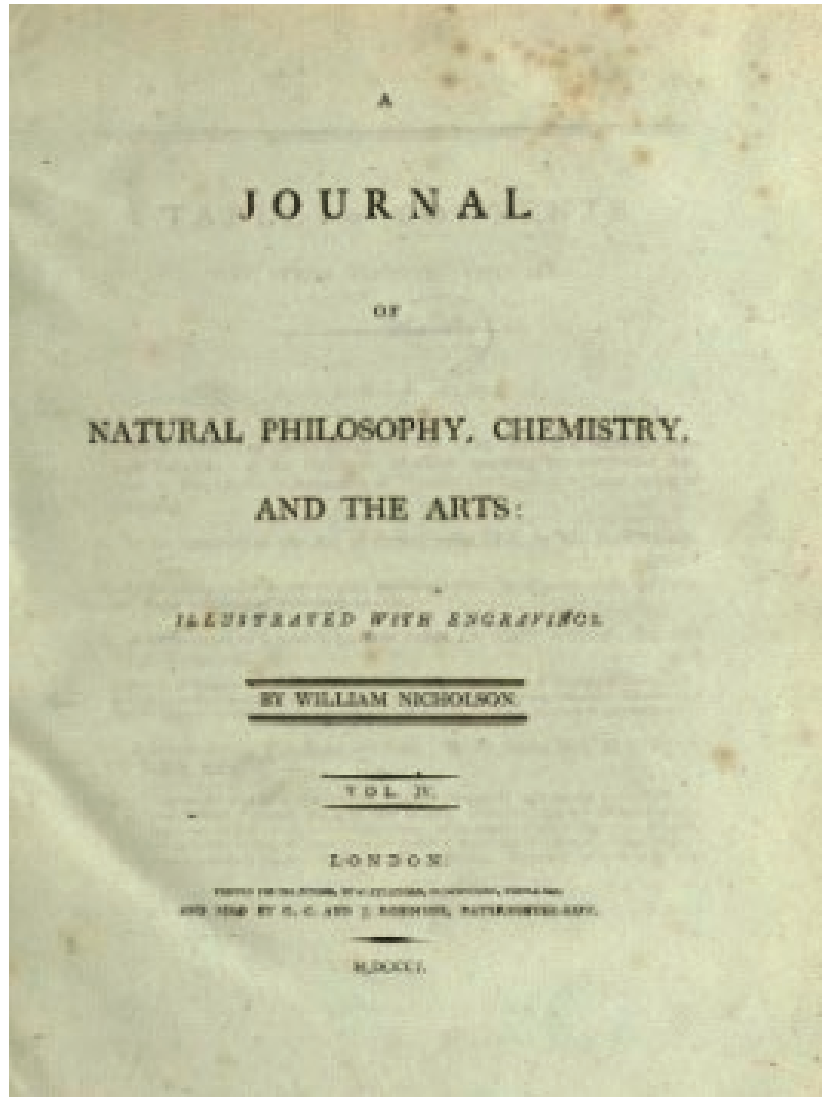

Figure 1. Title page of the remarkable Volume IV of Journal of Natural Philosophy, Chemistry and the Arts, called Nicholson's Journal. In this Volume from 1801, in the six issues from July to December 1800 the notable number of 13 papers (out of a total of 58) were published which exclusively dealt with galvanic action.

topic, remarkably as early as July 1800 in Nicholson's Journal. ${ }^{[1]}$ Cruickshank began his experiments by repeating those of Nicholson and Carlisle, albeit with another device. Briefly, he used a horizontally placed glass tube, completely filled with water, with both openings closed with cork stoppers. ${ }^{10}$ Then he inserted wires made from silver through the corks at each end into the water and connected them with a voltaic pile composed from plates of silver and zinc. After completing the cir-

1765 he received his master from King's College in Aberdeen and later a diploma from the Royal College of Surgeons of England. In 1788 he got a position as assistant at the Royal Military Academy, and as lecturer in 1796 until 1804 . He died in 1810 or in 1811 in Scotland. In addition to his first theory of the decomposition of water, he invented the trough battery. ${ }^{[12]}$

${ }^{10}$ Unfortunately, in the original paper in Nicholson's Journal the drawings of the devices were not printed, because Cruickshank missed the deadline to submit them. Their schematic reproductions are found in the comprehensive and detailed study about electricity from 1751 till 1807 by Amy Alice Fisher. ${ }^{[13]}$ cuit, he observed that gases were evolved at the two poles, with hydrogen at the silver wire and oxygen at the zinc wire. ${ }^{11}$ In addition, he observed corrosion of the zinc wire. Upon adding a tincture of litmus or Brazil wood, and carrying out the experiment again, he observed that at the zinc wire the water became acidic, at the silver wire alkaline, effects that were noted also by others. He decomposed also "metallic" solutions, that are solutions of salts of metals. With silver dissolved in nitrous acid he got a precipitate of needle-like crystals in the form of arbor Dianae. ${ }^{12}$

In the same paper he tried to find out how far the influence of galvanic electricity is reaching. To this end, he connected two tubes described above for their communication by a silver wire, a 1st class conductor, that was passed through a cork of each tube. After closing the circuit, he observed the usual corrosion or disengagement of gases at the poles, what convinced him that an even greater number of tubes connected in series would give a similar result.

In the subsequent article in the issue of September $1800,{ }^{[14]}$ Cruickshank addressed that significant problem which was incomprehensible since its discovery: the occurrence of the individual gases in the water at the two different poles when galvanic current is applied. To attempt to solve this, Cruickshank used single tubes as described above, and carried out a series of quantitative measurements of the gases which evolved under various conditions. Based on his findings he formulated the first theory of the transport of the particles which were decomposed during electrolysis (ref. ${ }^{[14]}$, pp. 257, 258). For water as liquid, Cruickshank hypothesized that the "galvanic influence (whatever it may be) is capable of existing in two states, that is, in an oxygenated and deoxygenated state". Since its affinity for oxygen is weaker than for solid metals, Cruickshank assumed that upon

${ }^{11}$ One has to differentiate Cruickshank's designation of the metals of the wires inserted into the liquid in which decomposition occurs, on the one hand, and of the plates of the voltaic pile, on the other hand. This terminology was later used by others, but not by everyone. Cruickshank, who applied the common configuration of the pile, which was made from plates of silver and of zinc, did not define the poles as positive or negative. He stated instead; "In future, to avoid circumlocution, I shall call the wire attached to the silver plate, the silver wire, and the other the zinc wire." This terminology did not define the metal of the wire (e.g. gold, silver, platinum, iron, etc.), which was occasionally used as pole immersed into the liquid under study, it refers to the metals of the pile's plates onto which the wires were attached. We will italicize these wires regardless of their metal. In the present example, it could be confusing because both wires consist of silver.

12 arbor Dianae, Lat. tree of Diana, also philosopher's tree, Lat. arbor philosophica, the silver tree, is formed when silver is precipitated from a silver salt solution by reduction. It has a shape like a tree, and consists of crystals of silver or silver amalgam. These trees were named by alchemists relating to the name for silver, Diana. 
the deoxygenated "galvanic influence" (probably somewhat like a galvanic electric fluid) from the silver wire enters the water, disrupts it into its components and seizes the free oxygen, whereby hydrogen gas is segregated. Then, the electric fluid, together with the oxygen, passes the water to the opposite pole, where the oxygen is transferred to the zinc wire, and is released as a gas. Eventually, after transmission of the oxygen, the deoxygenated electric fluid flows back to the pile. Note that Cruickshank believed that the two evolving elements came from the same water molecule.

In case that the interposed liquid is a solution of a salt from a metal, the deoxygenated electric fluid passes from the silver wire, seizes the oxygen of the metal calx, transports it to the zinc wire, where oxygen is released and the deoxygenated electric fluid enters the metallic pole.

Yet, Cruickshank recognized the somewhat inconsistent suppositions of his theory, and finally conceded:

"In reflecting on these experiments it would appear, that (....) the water must be decomposed; but how this can be effected, is by no means so easily explained. For example, it seems extremely mysterious how the oxygen should pass silently from the extremity of the silver wire to that of the zinc wire, and there make its appearance in the form of a gas." (ref. ${ }^{[14]}$, p. 257; note the attribution "extremely mysterious.")

In the aforementioned Vol. IV of Nicholson's Journal also other researchers, e.g. William Henry, Col. Henry Haldane and Humphry Davy reported the electrolysis of water, and all agreed that water is a compounded body, composed from about two parts of hydrogen and one part of oxygen. However, one researcher, Johann Wilhelm Ritter from Jena in Germany, one of the most passionate followers of the Romantische Naturphilosophie (Romantic Nature Philosophy), ${ }^{13}$ was strictly convinced that water was an undecompounded body, a chemical element.

2.1.2 September 1800: J. W. Ritter's theory of the metamorphosis of water by galvanic action

Johann Wilhelm Ritter was the opponent of the current hypothesis of the electrolysis of water (please pay heed to footnote ${ }^{14}$ ) He believed that water does not

\footnotetext{
${ }^{13}$ Ritter was strongly influenced by Friedrich Wilhelm Joseph Schelling, the main philosopher of the Romantischen Naturphilosophie "The Romantic Nature Philosophy considered the human being as a whole in the system of nature. Philosophy provided a system of thought from which the events of nature observation can be read." Transl. from ref. [15], p. 23. ${ }^{14}$ Johann Wilhelm Ritter (1776, (Samitz (Zamienice) near Haynau (Chojnów), Silesia - 1810, Munich) was a German physicist (initially
}

decompose under galvanic action and therefore formation and migration of ions do not occur. That may sound like a paradox, taking into account that he was the first researcher in Germany who experimentally fractionated water into gaseous hydrogen and oxygen using galvanic electricity. We find him noteworthy in the present historical retrospect not only because he pioneered the research in galvanism in Germany (together with Theodor von Grotthuß, see below), but also, due to his outstanding and unusual personality in the scientific community. He was a somewhat strange person of vivid imagination, unusual mental agility and seemingly borderless inventive creativity. ${ }^{15}$ Humphry Davy, for example, characterized Ritter's person and activities in his Bakerian lecture in 1826 (ref. ${ }^{[21]}$, p. 385) as follows:

"Ritter's work contains some very ingenious and original experiments on the formation and powers of single galvanic circles; (...) : and in the obscurity of the language and metaphysics (.....), it is difficult to say what may not be found. In the ingenious, though wild views, and often inexact experiments of Ritter, there are more hints which may be considered as applying to electro-magnetism than to electro-chemistry, ..."

Without having a regular income, Ritter began his research, notwithstanding the problems of getting access to the current literature sources in Jena ${ }^{16}$ where he conducted his scientific and philosophical studies. ${ }^{[24]} \mathrm{He}$ carried out his experiments knowing only how to put a voltaic pile together, but without having knowledge of comparable experiments that were already done. Nonetheless, he was able to complete his investigations and to publish his results as early as in September 1800, ${ }^{[25]}$ remarkably just two months after Nicholson and Carlisle, and at the same date when Davy had completed his first experiments on this subject - albeit under relevantly better conditions. In his first experiments he subjected water to galvanic action with a simple, self-made device, and measured quantitatively the volumes of the two gas-

he was an apothecary), philosopher and an extraordinarily multifaceted personality. He can be considered as an outstanding scientist, but till at present time he is quite underestimated. Without never getting a position at a university (he only became member of the Bavarian Academy of Science in 1804, see his portrait in Figure 2) he contributed as autodidact to galvanism, e.g. by the independent discovery of the electrolysis of water in September 1800. In the course of these experiments, he invented electroplating. He discovered UV-radiation in 1801, [16]. and invented the dry cell battery in 1802. Ritter built the battery from 600 zinc-copper plates. It reached a potential of more than 700 Volt. In the last years of his live his interest turned, influenced by the German theosophist Franz Xaver von Baader, to siderism and radiesthesia. ${ }^{[17],[18],[19] .}$ He died in poverty at the age of 33 by tuberculosis.

${ }^{15}$ The character of the protagonist is borrowed from the real person Johann Wilhelm Ritter in the novel "Die Unglückseligen" (The Unfortunate Ones) by the German woman writer Thea Dorn. ${ }^{[20]}$

${ }^{16}$ See e.g. his letter to Horkel. ${ }^{[23]}$ 


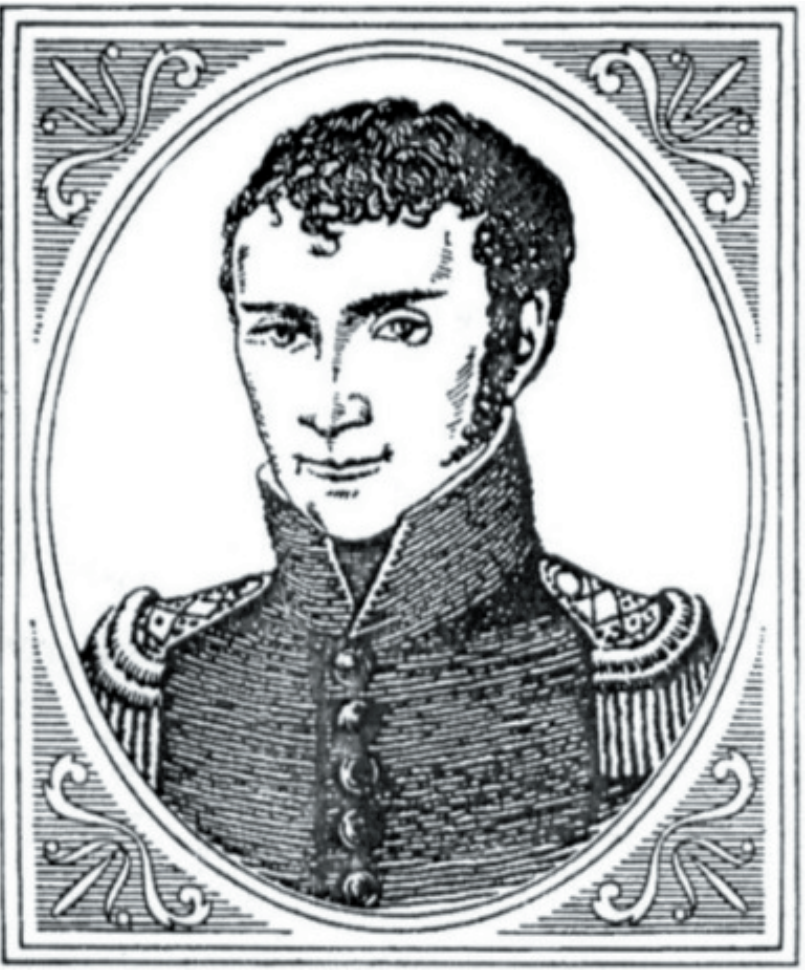

Figure 2. Portrait of Johann Wilhelm Ritter, wearing the uniform of the Bavarian Academy of Sciences. About 1804. Unknown artist. Taken from ref. ${ }^{[22]}$.

es which were separately generated at the electrodes by collecting them in two tubes after closing the circuit. ${ }^{17}$ Although Ritter identified the two gases as oxygen and hydrogen in roughly the correct proportions of one to two and a half volumes, he asked himself the same question that British researchers did, namely

"Kann sich aber das nemliche Atom Wasser in einem und dem nemlichen Augenblicke zugleich an diesem und wieder an jenem Drathe befinden ? - Und doch müßte das der Fall seyn, wenn beyde Gasarten, beyde Stoffe, das Oxygen und Hydrogen, von einer wirklichen Zersetzung des Wassers herrührten." (But can the same atom of water be on this and on that wire at the same moment? - And yet this would have to be the case if both types of gas, both substances, oxygen and hydrogen, resulted from a real decomposition of water.)

Ritter could ignore this problem because he believed that water was an element and not a molecule. He was

\footnotetext{
${ }^{17}$ A drawing of this device is depicted on p. 372, (Fig.3, Tab.V) of Voigt's Magazin, ref. ${ }^{[25]}$. The complete name of this little-known journal was Magazin für den neuesten Zustand der Naturkunde mit Rücksicht auf diedazu gehörigen Hilfswissenschaften, herausgg. von Johann Heinrich Voigt.
}

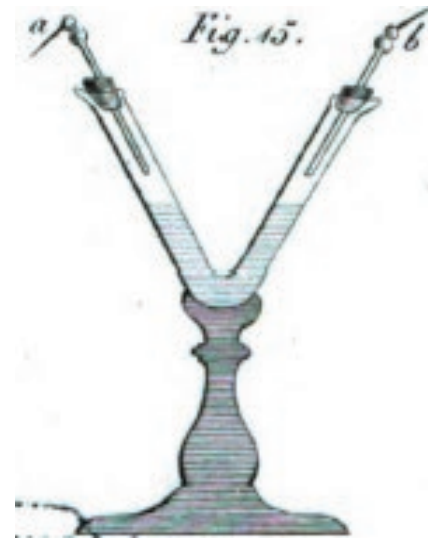

Figure 3. The V-shaped glass tube with side pieces of 2 German inches (i.e. about $3 \mathrm{~cm}$ ) in length was first filled halfway with pure concentrated sulphuric acid. The acid was then overlaid with distilled water, into which the two poles $a$ and $b$ were dipped. The poles, made from gold, were connected with the voltaic pile. Taken from ref. ${ }^{[26]}$, after p. 326, Taf. 1, Fig. 15.

convinced that the collected hydrogen and oxygen were not decomposition products of water, but they were still water which was transmuted into other forms. As a proof for his conviction he filled a V-shaped glass tube (depicted in Figure 3) halfway with concentrated sulphuric acid, and covered the acid meticulously on both side pieces with distilled water, taking care to avoid any mixing of the two liquids. ${ }^{[25]}$ The acid was intended to act as a barrier to prevent the transfer of water or of its components through the acid and thus to the opposite side piece. To this end he selected concentrated and rectified sulfuric acid after testing that it did conduct electricity, ${ }^{18}$ but did not evolve even a trace of gas under the action of galvanic electricity.

Ritter dipped one pole through the one, the other pole through the other opening of the tube into the water, completed the electric circuit, and observed the immediate and separate formation of gaseous hydrogen and oxygen at the individual poles ( $a$ and $b$ in the original "Fig. 15") without any gas showing anywhere else in the tube between $a$ and $b$.

After he had executed several similar experiments and obtained the same results; he concluded (p. 390)

"So ist es also durch Versuche nun nicht bloß auf das Vollständigste erwiesen: daß die bey der Einwirkung des

\footnotetext{
18 The conscientious experimenter Michael Faraday found the very reverse and explained "681. On experimenting with sulphuric acid, I found no reason to believe that it was by itself a conductor of, or decomposable by, electricity" and continued "When very strong it is a much worse conductor than if diluted". ${ }^{[10]}$. This comment suggests that Ritter's sulphuric acid still contained traces of water.
} 
verstärkten Galvanismus auf Wasser erzeugten beyden Gasarten, das Hydrogen wie das Oxygen, keinesweges von einer sogenannten Zersetzung des Wassers herrühren können, sondern überdies noch: daß auch die Erzeugung jeder einen Gasart ein Proceß sey, der ganz und gar nicht mit dem der Erzeugung des anderen zusammenhänge, sondern daß, beyde durchaus unabhängig voneienader, und einzeln, Statt haben können." (Thus, it is not only proved to the most complete extent by experiments: that the two types of gas, hydrogen and oxygen, produced by the action of the amplified galvanism on water can't at all result from a so-called decomposition of water, but, moreover, that the generation of each type of gas is also a process which is in no way connected with that of the generation of the other, but that both can take place entirely independently of one another and individually.)

These results convinced Ritter once and for all to have demonstrated that water on both sides was in fact independently transmuted by a kind of metamorphosis into another modification by electricity, but not decomposed. ${ }^{19} \mathrm{He}$ took this result as evidence that oxygen is water minus electric fluid, and hydrogen is water plus the electric fluid, but they still remain elemental water.

A severe disadvantage to follow Ritter's argumentation was his circuitous and protracted style of writing, which was very difficult to understand - even for native speakers. This peculiarity was communicated by the Anglo-Irish physician and mineralogist William Babington $^{20}$ in a letter dated December 1800, entitled "On the State of Galvanism and other Scientific Pursuits in Germany" and printed in Nicholson's journal. ${ }^{[27]}$ Nevertheless, von Grotthuß acknowledged Ritter (ref. ${ }^{[28]}$, p. 113) that he - although he never graduated from university - possessed the ability and acumen to refute all theories proposed prior to 1805 about the flow of electricity during the electrolysis of water (see ref. ${ }^{[29]}$ ).

\footnotetext{
${ }^{19}$ Ritter carried out all these experiments in Jena within days, namely from September 28 to 30, 1800 .

${ }^{20}$ William Babington (1756, Portglenone near Coleraine, Irland - 1833) reported, for instance, in his letter to the editor: "...The principal galvanic discoverer here is a young man, called Ritter, at Jena, in Saxony: about two years since he published the result of his almost innumerable experiments, in which he established all its laws, and anticipated almost all the newer experiments. Unfortunately the book was written very obscurely, and was still more obscured by the language of the newer philosophy. ..... this suggested to him to interpose some substance between the extremities of the wires, which was at the same time capable of conducing the galvanic influence, and of remaining perfectly unaltered by it. .... thus it is proved, that water under certain circumstances, may be wholly converted into oxygen gas, and under others, into hydrogen-gas; the rationale of this phaenomenon is as yet in obscurity". The present author illustrates his intricate and circuitous style by one example taken from pages XXI and XXII of his book about Siderism: one single sentence, which is composed of many subordinate clauses and nested sentences, consists of the remarkable number of 297 words. ${ }^{[17]}$
}

Ritter published his theory in September 1800, at exactly the same date as Cruickshank. So there are two philosophers who could have claimed priority, although their theories could not be more different, but the credit goes to only Cruickshank. Only his theory deals with the motion of particles, a criterion of electrophoresis. However, in the end, Cruickshank's theory as well as Ritter's theory of the "Einfachheit des Wassers" ("elementariness of water") ${ }^{[24,30]}$ soon failed due the investigations of Davy, von Grotthuß, and others.

\subsection{Other theories from 1800 till 1805}

In autumn 1800 Humphry Davy, too, wondered whether the formation of oxygen or hydrogen gas took place when the water is filled into separate vessels (each connected to the pile with a wire). The water was not in direct contact in Davy's experiments either, but in contrast to one of Cruickshank's devices (in which the two tubes were connected by a silver wire), it communicated through 2nd class conductors. ${ }^{[31]}$ First, Davy closed the electric circuit by dipping the fingers of his right and his left hand into the water in the separate vessels, and observed the disengagement of gases at the poles. The gases were also generated when communication was through three persons, or by connecting the two vessels with muscular or living plant fibers, respectively, or with moistened thread, all acting as 2 nd class conductors. This result led him to conclude that not only galvanic current in the metallic wires, but also the flow of the current by electrified bodies in the connecting wet organic matter enabled the communication of the water in the separate vessels.

Davy investigated, in addition to that of water, the electrolysis of aqueous solutions of various acids and bases. He found, among other effects, that pure hydrogen was always generated at the one pole, but at the other pole oxygen was either released as gas or it oxidized the metal of the wire. He published his results between September and December 1800 in three papers in the notable Vol. IV of Nicholson's Journal mentioned above. ${ }^{[31-33]}$

Nevertheless, after having executed numerous experiments Davy restrainedly summarized in December 1800 his attempts to clarify these difficult to understand invisible motion through water and other menstrua. He stated (ref. ${ }^{[33]}$, p.400)

\footnotetext{
"Many new observations must be collected, probably before we shall be able to ascertain whether water is decomposed in galvanic processes. Supposing its decomposition, we must assume, that at least one of its elements is capable of rapidly passing in an invisible form through
} 
metallic substances, or through water and many connected organic bodies; and such an assumption is incommensurable with all known facts."

It is worth noting that at the turn of 1800 to 1801 in Germany four researchers independently realized that the order of the metal plates on the voltaic pole built by earlier philosophers was misleading. In the past, the pile was composed of plates of zinc (Z) and silver (A) with an interposed wetted layer $(\mathrm{w})$ in the sequence [-SZwSZw... SZwSZ+]. But K. W. Böckmann, ${ }^{[34]}$ A. von Arnim, who entitled his paper "Über die Benennung der Endpole der Voltaische Säule" (On the designation of the end poles of the Voltaic pile), ${ }^{[35]}$ P. Erman ${ }^{[36]}$ and W. Gruner ${ }^{[37]}$ discovered that the proper sequence of the pile should be $\left[-Z_{w S Z w S} . . \mathrm{ZwS}+\right]$, which is obtained by omitting the zinc and the silver plate, respectively, at the two extremities of the earlier pile. ${ }^{21}$ We can especially recommend reading the expounded and informative comments of the highly competent editor of Ann. Phys., Ludwig Wilhelm Gilbert, on Erman's ${ }^{[38]}$ and on von Arnim's ${ }^{[39]}$ contributions. $^{22}$

However, at the European Continent several other theories of electrolysis and the electrophoretic current were formulated in these years. This happened for the most part in Germany, France, Italy, and in Sweden. In Germany, among others, Paul Ludwig Simon (1771 - 1815, Berlin), professor at the Building Academy in the faculty of architectural physics in Berlin, ${ }^{[40,41]}$ and Christian Heinrich Pfaff, professor of medicine, physics and chemistry in Kiel, ${ }^{[42]}$ stepped forward with theories of the action of electricity on water which are not going

\footnotetext{
${ }^{21}$ Karl Wilhelm Böckmann (also Boeckmann) (1773 - 1821, Karlsruhe), physicist and chemist, professor for physics. (Carl Joachim Friedrich Ludwig) "Achim" von Arnim (1781, Berlin - 1831, Wiepersdorf), Göttingen. Paul Erman (1764 - 1851, Berlin), professor for physics in Berlin. Johann Ludwig) Wilhelm Gruner (1771, Halle on Saale - 1849), court apothecary in Celle.

${ }^{22}$ In von Arnim's paper Gilbert (1769, Berlin - 1824, Leipzig) wrote as a part of a comprehensive comment somewhat caustically: “... Wenn also Nicholson seine Voltaischen Säulen auf folgende Weise errichtet: S., Z., fL., S., Z., fL., S....Z., fL., S., Z., so sind die erste Silber- und die letzte Zinkplatte der Säule offenbar überflüssig und nicht als Glieder der galvanischen Ketten, sondern bloß als ein willkürlich hinzugefügter Metalleiter zu betrachten, der, ohne etwas zu ändern, so gut fehlen als da seyn kann. Nach ihnen den ersten Pol den Silberpol, und den letzten den Zinkpol zu nennen, wie man es bisher gethan hat, ist daher gewiß unschicklich und verwirrend, ... " (So if Nicholson builds his voltaic pile in the following way: S., Z., fL., S., Z., fL., S....Z., fL., S., Z., the first silver- and the last zinc plate of the pile is evidently superfluous but to be considered merely as an arbitrarily added metal conductor, which can be lacking as well as be present, without changing anything. Terming the first pole the silver pole and the last the zinc pole, as has been done thus far, is therefore certainly improper and confusing. ... ). [fL. stands for the wetted layer; the
} author]. to be discussed further. ${ }^{23}$

In France A. F. Fourcroy, L.- N. Vauquelin and L. J. Thénard ${ }^{24}$ published a number of papers in Magasin Encyclopédique, ou Journal des Sciences, des Lettres et des Arts. In 1800 and 1801. In 1801 Citoyens Fourcroy and Vauquelin hypothesized the circulation of the electric fluid from the positive to the negative pole. They assumed that this fluid decomposes water at the positive wire, where oxygen is released as gaseous bubbles. There, the positive fluid combines with hydrogen, and the combined hydrogen is transported unseen by an assumed fluidum deferens, the galvanique, to the negative wire. The galvanique enters this wire, whereupon the hydrogen is evolved as gas bubbles. ${ }^{25}$

An "electric acid" ("l'ossielettrica"), an expansive liquid with fineness like heat and light, smelling similar to phosphorus, and tasting pungently was conjectured in 1800 by Luigi Valentino Brugnatelli (1761 1818, Pavia), professor of chemistry in Pavia, Italy, and friend of Volta. ${ }^{[44,45]}$ According to his theory, the electric acid easily enters the metals, and dissolves them - such as water dissolves a salt - as soon as it is set in motion ("quando l'osielletrico é in moto"). It is soluble in water, and in such a dissolution most metals are oxidized at the expense of water, whereupon hydrogen is formed through decomposition. The metal oxides formed by this reaction combine with the electric acid under formation of metal électrates ("osielettrati"). For example, the électrate of copper is green, that of silver is white, both are transparent and insoluble in water. Their most pronounced capability is that they can be carried away through the water by the electric acid over comparably long distances. Finally, the électrates are precipitated at the metal of the pole as salt-like crusts. ${ }^{26}$

\footnotetext{
${ }^{23}$ Paul Ludwig (also Paul Louis) Simon (1771, Berlin - 1815, Berlin); Christoph Heinrich Pfaff (1773, Stuttgart - 1852, Kiel).

${ }^{24}$ Antoine François, comte de Fourcroy (1755 - 1809, Paris); Louis-Nicolas Vauquelin (1763 - 1829, Saint-André-d'Hébertot, Normandy); Louis Jacques de Thénard (1777, La Louptière, near Nogent-sur-Seine (Aube) - 1857, Paris).

${ }^{25}$ Their hypothesis is published in Séance publique de l'Ecole de mêdicine de Paris, du 24 vendemiaire an 10, [Sept. 24,1801; the author] in- $4^{\circ}$., page 67. and reads: "Les CC. Fourcroy et Vauquelin, ..., admettent l'existance d'un fluide particulier, qu'ils nomment galvanique, et qui circleroit du côté positif de la pile, vers le côté négatif. Selon eux, ce fluide décompose l'eau en sortant du côté positif: il laisse échaper l'oxygène en bulles; mais il se combine avec l'hydrogène pour former un liquid, lequel traverse l'eau, ...., pour aller gagner l'extrémité du fil négatif. Là le galvanique abandonne son hydrogène, et le laisse échapper à son tour sous forme de gaz, tandis que lui-même pénètre dans le fil." (ref. ${ }^{[43]}$, p. 157.$)$ ${ }^{26}$ Alessandro Volta explicitly distanced himself from Brugnatelli's theory and stated in ref. [46]., p. 264, "Ich habe keinen Antheil an seinen Meinungen oder Ideen über die electrische Säure, die electrisch-sauren Metalle, u.d. m." [Ann. Phys. (Gilbert ed.) XIV (7), p. 264.] ("I have no share in his opinions or ideas about the electric acid, the electric-acidic metals, etc)."
} 
To his surprise, when he visited Paris with Volta, Brugnatelli found a paper in the issue of August, 1801 (le 11 fructidor an 8) of Ann. Chim., authored by the Belgian Étienne-Gaspard Robert. Around 1800 Robert executed experiments with galvanism, and read one of his works before l'Institut National de France in August 1801, which was published in the aforementioned Ann. Chim., entitled "Expériances nouvelles sur le fluide galvanique". ${ }^{[47]} \mathrm{He}$ proposed a theory which was very similar to Brugnatelli's, ${ }^{27}$ and in which he termed Brugnatelli's electric acid "l'acide galvanique".

Robert was well-known by his stage name Stephan Kaspar Robertson, also Robert-son, ${ }^{28}$ whereby it was peculiar back then as it is today, why ask a professor of physics would choose a stage name. ${ }^{29}$

Due to his interest in many various areas. it was not surprising that the German physician Johann Friedrich Erdmann was fascinated by the recently discovered galvanic electricity, and in its applications to medical issues. ${ }^{30} \mathrm{He}$ decomposed water by electrolysis and obtained hydrogen and oxygen in right proportions as usual. In 1802 Erdmann put forward the hypothesis that galvanic electricity flows into the water at the + pole, and leaves it at the - pole. ${ }^{[56]}$ By entering water at the + pole, it binds hydrogen, since the latter has a larger affinity to electricity than to oxygen, and thus oxygen is liberated. Hydrogen unites to hydrogenated electricity,

\footnotetext{
${ }^{27}$ Chapitre X. Expériences et observations sur le galvanism, par MM. Nicholson, Carlisle, Robertson, Cruickshank, Henry and Davy; ref. [48], p. $282 \mathrm{ff.}$ §. II. Expériences et observations de M. Robertson, see p. 294.

${ }^{28}$ The hyphen in Robert-son is not a printing error.

${ }^{29}$ Robert had a remarkably eventful biography (see his Mémoires). ${ }^{[49], 50] .}$ Born in 1763 as Étienne-Gaspard Robert in Liège, Belgium, he studied at Leuven, and became professor of physics, specialized in optics, at lécole centrale du département de l'Ourthe. In 1791 he moved to Paris to strive for a career in art as a painter. There, he attended in 1792 and 1793 the scary ghost-raising show Phantasmagorie, and easily figured out that the ghosts were created by the use of a Laterna Magica. He premiered his own show (under the stage name Robertson) in Paris in 1798 which he later performed with great success around the world. During these trips he became fascinated by ballooning and flew balloon shows in Vienna, Dresden, Leipzig, Moscow and other cities. He considered some flights by himself as being scientific, because he connected them with meteorological investigations. He managed to publish three of his flights in Ann. Phys. in 1804 as communications to the editor

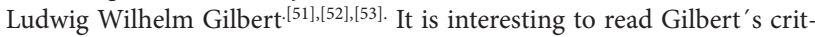
ical comments and references to errors in Robertson's reports, which make up a large part of the papers. Robert died in 1837 in Paris.

${ }^{30}$ Erdmann (1778, Wittenberg - 1846, Wiesbaden) published, for instance, in 1803 , one year after his doctorate in medicine, a paper entitled "Beschreibung zweier von Dr. Brunner in Wien erfundenen voltaisch-elektrischen Apparate zur Entdeckung des Scheintodts und zur Wiederbelebung der Scheintodten" (Description of two by Dr. Brunner in Vienna invented voltaic-electrical apparatus to discover the apparent death and to revive the apparent dead), ${ }^{[54]}$ and in 1804 one about "Galvanische Versuche, angestellt im Wiener Irrenhaus"(Galvanic experiments, employed in the Vienna madhouse). ${ }^{[55]}$
}

which traverses the liquid towards the - pole, where the electric matter intrudes the metal of the pole and hydrogen is released as gas. ${ }^{31}$

Since in the first years after 1800 the subject of most of the works was the decomposition of solutions of arbitrarily chosen salts, acids and bases by galvanic electricity, it was quite difficult to find a coherent structure in the results obtained under these widely varying conditions. This gap motivated the Swedes Wilhelm Hisinger and Jöns Jacob Berzelius "to search for as many as possible general results from the experiments we and others have performed, so that the phenomena" of the electric decomposition and the motion of the ions could be better understood and even foreseen (ref. ${ }^{[57]}$, p. 115 - 116). They published a systematic study of nearly thirty selected electrolytes in 1803 in German translation ${ }^{[57]}$ from Swedish and in 1804 in a condensed version in French. [58] It can be said that this work did not contain really new aspects, but the categorization of the experimental outcomes enabled them to formulate certain valuable rules, which they summarized in seven points. We cite those rules which have a direct context to the motion of decomposed particles. They read ${ }^{32}$

"Versuch, aus den obigen sowohl, als aus anderen bekannten galvanischen Versuchen, einige allgemeine Folgerungen herzuleiten. 1. Wenn sich die electrische Säule durch eine Flüssigkeit entladet, so sondern sich die Bestandtheile dieser Flüssigkeit dergestalt von einander $a b$, daß sich einige von ihnen um den negative Pol, andere um den positiven ansammeln. 2. Diejenigen Stoffe, die sich zum Drahte eines und desselben Poles hin begeben, stehen unter sich in einer gewissen Analogie. Zum negativen Pol gehen alle brennbaren Körper, Alkalien und Erdarten; zum positiven hingegen Sauerstoff, Säuren und oxydierte Körper. 7. Wasser wird in Wasserstoff und Sauerstoff zerlegt, die aber in unzerlegtem Wasser unauflöslich sind, daher ersteres vom negativen, letzteres vom positiven Draht, gasförmig entwickelt wird." (Attempt to draw some general conclusions from the above, as well as from other known galvanic experiments. 1. If the electric column is discharged through a liquid, the components of this liquid separate from one another that some of them collect around the negative pole, others around the positive. 2. Those substances which move to the wire of one and the same pole stand in a certain analogy among themselves. All combustible bodies, alkalis and earths go to the negative pole; to the positive, on the other hand, oxygen, acids and oxidized bodies 7 . Water is fragmented

\footnotetext{
${ }^{31}$ This paper was an extract of his doctoral thesis entitled "Utrum aqua per electricitatem columnae a cel. Volta inventae in elementa sua dissolvatur?", which he defended on May 2, 1802, at the Medical Faculty of the famous Alma mater Wittenbergensis.

${ }^{32}$ Points $3,4,5$ and 6 are not directly relevant for the topic at hand, therefore we leave them out.
} 
into hydrogen and oxygen, which, however, are insoluble in undecomposed water, so the former is developed in gaseous form from the negative, the latter from the positive wire.).

Hisinger and Berzelius interpreted their findings as the result of the electrostatic attraction and repulsion of the ions to and from the respective charged poles. ${ }^{[57]}$ They assumed these electric forces to follow the principle of the action at a distance. In the concept of the action at a distance ${ }^{33}$ the forces are strongest at their poles and diverge then in the inverse ratio of the square of their distance. The two forces cross in the middle between the poles and compensate each other at the point of neutrality or indifference point. Decomposition happens not at the poles, but near or at this point. This concept was later a key part of Humphry Davy's theory of the electrolysis and the motion of the decomposed particles. ${ }^{[62]}$

Hisinger and Berzelius were not really convinced of this hypothesis. They doubted the assumption of decomposition at the point of indifference, as this contradicted what was observed in practice (ref. ${ }^{[57]}$, p.148) Therefore, skeptical about their still unsatisfactory results, they concluded

"Wir wagen kein Raisonnement über das Wie der obigen Zerlegungen. Doch scheint uns am meisten natürlich, dieselben durch Attraction der Electricität, die sie auf gewisse Stoffe, und Repulsion, ${ }^{34}$ die sie gegen andere äußert, zu erklären, ob uns gleich diese Erklärung wenig genügend scheint." (We do not dare upon making any reasoning about how the above decompositions are made. Yet it seems to us most natural to explain them by the attraction of electricity, which it expresses for certain substances, and repulsion, which it expresses against others, although this explanation seems little sufficing to us.)

However, none of the theories proposed thus far had been considered as generally valid due to contradictions and inconsistencies, and the confusion about the transport of hydrogen and oxygen. The question of the flow of the electric current through water during its decomposition remained. But in 1805, this patchwork of disorientating theories was resolved by the - surprisingly - only twenty years old German student Theodor von Grotthuß.

\footnotetext{
${ }^{33}$ The concept of the action of a distance, expressed also as the inverse square law, applied to Newton's law of universal gravitation, ${ }^{[59],[60]}$ and to Coulomb's laws for the electrostatic repulsion of equally charged and the attraction of oppositely charged points. ${ }^{[61]}$

${ }^{34}$ They relativized on p. 148, footnote 3: "Daß unter Repulsion richtiger eine geringere Verwandschaft als eine wirkliche Zurückstoßung zu verstehen sey, wird man leicht einsehen". (It will be easy to see that by rejection it is more correct to mean a lesser relationship than an actual rejection.)
}

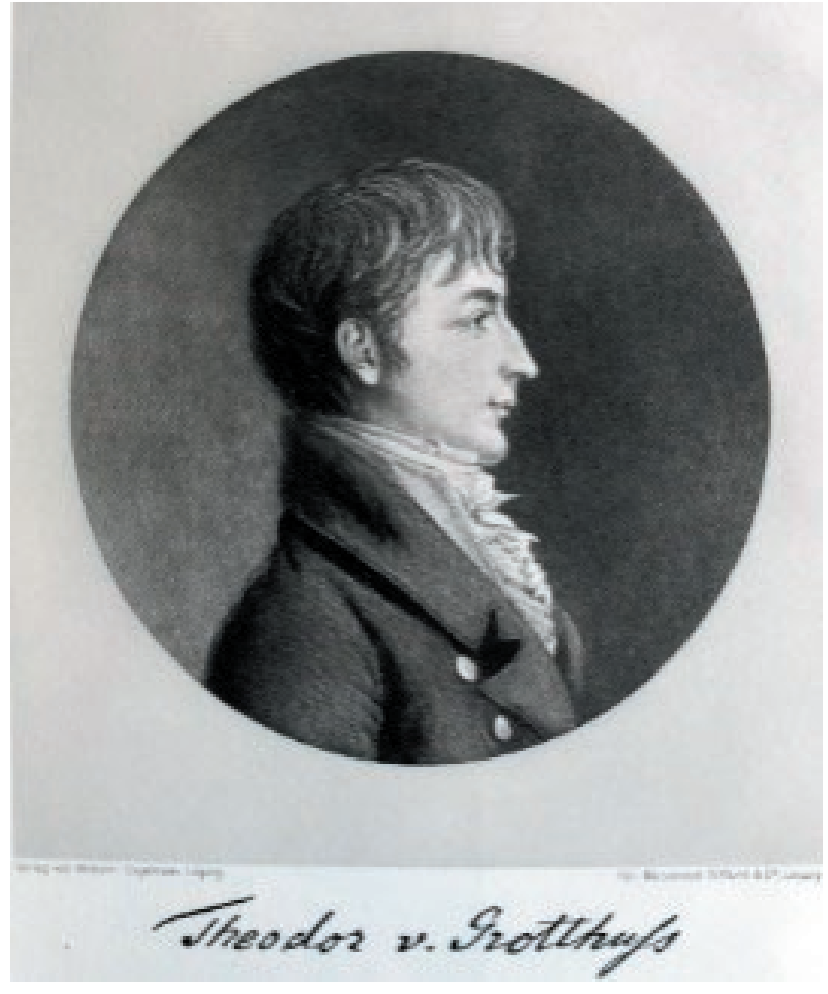

Figure 4. Portrait of baron Christian Johann Dietrich Theodor von Grotthuß (C. J. Théodore de Grotthuss). Photogravure by Meisenbach and Riffart \& Co. in Leipzig, produced prior to 1894, undated.

2.3 1805: C. J. T. von Grotthuß' theory of the electrophoretic current during the electrolysis of water and of the bodies which it holds in solution

During his stay as a student of natural sciences in Italy from 1804, baron Christian Johann Dietrich Theodor von Grotthuss (also C. J. Théodore de Grotthuss) ${ }^{35}$ formulated a theory that made him highly recognized, in particular that of the flow of electricity during the decomposition of water. His theory was so plausible to his contemporaries that, unlike the ones discussed above, it found general acceptance. It was compelling

\footnotetext{
${ }^{35}$ Christian Johann Dietrich Theodor von Grotthuß (1785, Leipzig, Germany - 1822, Geddutz (at present day Gedučiai), Lithuania. See his portrait in Figure 4), member of a German-Baltic noble lineage, began his university studies in Leipzig in 1803, and continued six months later at École Polytechnique in Paris, then from 1804 in Italy. He left Italy in 1806 and returned via Paris, Munich and Vienna in 1898 to his manor Geddutz in Courland. Since his return to his manor von Grotthuß tended to live secluded from the scientific community. There he continued his electrochemical research, and investigated the chemical effect of light. ${ }^{[63]}$. In 1819 he formulated the photochemical absorption law (named Grothuss-Draper law, or the Principle of Photochemical Activation; this law was independently formulated in 1842 by the English-born American scientist John William Draper). (for details, see e.g. ref. ${ }^{[64]}$ ).
} 
because it could provide an answer to the previous question how hydrogen or oxygen can traverse water in the form of a gas from one pole to the other. ${ }^{[65-67]}$

In Chapter II of "Mémoire sur la decomposition de l'eau et des corps qu'elle tient en dissolution à l'aide de l'électricité galvanique" which Grotthuß published in 1805 in Rome, ${ }^{[65]}$ and in 1806 in Ann. Chim. in Paris, ${ }^{[67]}$ he postulated that in each water molecule - he assumed that it was made of $(\mathrm{HO})$ - the hydrogen and the oxygen atom are positively and negatively polarized, respectively. ${ }^{36}$ Upon application of an electric potential the molecules orient themselves with their polarized atoms in direction of the oppositely electrified poles, forming a chain in the liquid in this way, schematically depicted by $\left(^{(+)} \mathrm{H}-\mathrm{O}^{(-)}\right)\left({ }^{(+)} \mathrm{H}-\mathrm{O}^{(-)}\right)$. In $\$$. 20. of his treatise, he formulated his basic idea as follows

"Il est clair que, dans toute cette opération, les molécules d'eau situeés aux extrêmités des fils conducteurs, seront seules décomposées, tandisque toutes celles placées intermédiairement, échangeront réciproquement et alternativement leurs principes composans, san changer de nature. J'en déduis que, s'il était possible d'établir un courant d'électricité galvanique dans de l'eau, de façon qu'il décrivit dans celle-ci une ligne parfaitement circulaire, toutes les molécules du liquide situées dans ce cercle, seraient decomposées, et a l'instant recomposées: d'où il suit que cette eau, quoique subissant l'effet de l'action galvanique, resterait toujours eau." (It is clear that, throughout this operation, only the water molecules located at the tip of the conducting wires will be decomposed, whereas all those located at intermediate positions will exchange their composing principles reciprocally and alternatively, without changing their nature. From this I deduce that if it were possible to apply a galvanic current in water such that it follows a perfectly circular line, all the water molecules of the liquid located in this circle would be decomposed and instantly recomposed: whence it follows that this water, although subjected to the effect of galvanic action, will always remain water. $)^{37}$

In Figure 5 the scheme of the mechanism of the flow of the electrophoretic current during the decomposition of water is depicted.

The U-shaped tube ("Fig. $1^{\text {er") }}$ ) is filled with water into which two poles connected to a voltaic pile are dipped. The water molecules are pictured as a series of circles with positive and negative charges, which is the stylized way of depicting von Grotthuß' real conception of a chain or row of polarized $\left({ }^{(+)} \mathrm{H}-\mathrm{O}^{(-)}\right)$molecules but does

\footnotetext{
${ }^{36}$ In his next paper dated $1807^{[68]}$. he depicted the water molecule as composed of one hydrogen and two oxygen, what he repeated in his work from 1811, ${ }^{[69] .}$ and from $1818 .{ }^{[70]}$

${ }^{37}$ The English version is published in ref. ${ }^{[71]}$
}

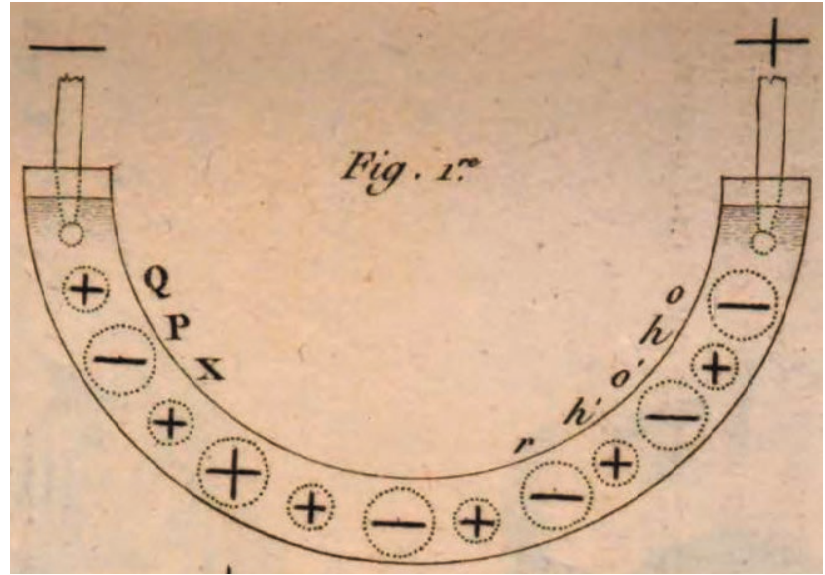

Figure 5. Schematic drawing illustrating Grotthuß' concept of the flow of the electric current during the electrolysis of water. "Fig. $1^{r e "}$ shows a U-tube filled with water, which forms of a chain of positively polarized hydrogen and negatively polarized oxygen atoms. It is important to realize that the circles with + and - signs are not ions, they are schematic depictions of the polarized atoms of the intact, neutral water molecules (which consist here from one hydrogen and one oxygen). During the complete process, free ions are not present in water. ${ }^{38}$ For a more detailed explanation see text. Taken from ref. ${ }^{[67]}$.

not display a sequence of ions since Grotthuß refused the presence of free ions from water. He believed that an ion is always associated with its oppositely charged ion. According to his theory, each of the elements of a molecule is subject to an attractive and a repulsive force, acting in contrary directions. The negative pole attracts the positively polarized hydrogen atom and repels the negatively polarized oxygen of the water molecules, the positive pole accordingly attracts oxygen and repels hydrogen. ${ }^{39}$ These electric forces are sufficiently energetic to overcome the chemical affinity in the terminal water molecules (that is to say, only in those at the ends of the chain). Considering for example hydrogen $Q$ at the end of the circular line (positive $Q$ of the water molecule $Q P$ at the negative pole in Figure 5), decomposition of molecule $Q P$ occurs, because it gives up its hydrogen $Q$, which is in direct contact with the pole, to the electricity of the negative wire. But at the same time as hydrogen atom $Q$ is liberated to hydrogen gas, the chain is instantaneously ("à l'instant") re-hydrogenated by hydrogen

\footnotetext{
${ }^{38}$ Comment of the author: In the fourth circle .after the minus pole of the tube in "Fig. 1" a minus should be inserted, not a plus; In the English translation of this paper in Phil. Mag. from 1806 this error was corrected, see Plate IX, Fig. 1 in ref. ${ }^{[66]}$

${ }^{39}$ Although Grotthuß initially assumed that the forces follow the inverse square law according to the action at a distance, he nevertheless believed that the atoms move with constant velocity, what is a contradiction in itself.
} 
$X$ of the adjacent molecule, a transfer which occurs in the same moment. Oxygen reacts analogue at the positive pole. It is decisive that only those atoms of the water molecules are segregated which are in direct contact with the poles. All other water molecules, which are between the poles, only exchange their atoms reciprocally, but do not change their nature. On these grounds, the flow of the electric current is caused by both kinds of atoms which continuously travel in opposite direction within the aligned chain of water molecules between the terminal atoms, forming an electrophoretic current in this way. The crucial fact of the matter is that ions are never present in their free form, because upon disintegration of the molecules the atoms bind immediately to the partner atoms of the next following molecules. Hence, all molecules in the solution are subject to the permanent and instantaneous process of decomposition and recomposition. ${ }^{40}$

It must be noted that Grotthuß initially assumed, but later withdrew, that the force of attraction or repulsion follows the action at a distance as Davy and Berzelius did. Yet, it is of paramount importance that Grotthuss' theory gave an answer to the apparently paradox effect of the evolvement of hydrogen and oxygen at the separate poles, because in his theory the evolved gaseous elements of water do not originate from the same water molecule and therefore do not travers the liquid. Grotthuß' theory was widely accepted ${ }^{41}$ but - to his annoyance - was initially attributed to the famous scientists Davy and Berzelius, and not to the unknown young German student. It took about fifteen years until Grotthuß asserted his priority on the theory in Volume 1 of his book entitled "Physisch-chemische Forschungen", [28] which he published in 1820, and in which he had collected his main scientific papers (Volume 2 did not appear anymore). This book can be regarded as his scientific testament, since two years later he committed suicide.

In the introductory commentary of his article from 1805 which he translated into German by himself in

\footnotetext{
40 The German translation and comments were published in 1808 by Johann Salomo Christoph Schweigger, professor of philosophy, physics and chemistry, and editor of Journal für Chemie und Physik. ${ }^{[72]}$

41 The author points out the following inconsistency in Grotthuß' description of his theory: according to this theory, negative oxygen $P$ combines after the release of positive hydrogen $Q$ with neighboring positive hydrogen $X$ under formation of the new molecule $\left({ }^{(+)} P-X^{(-)}\right)$. In this configuration, the negative oxygen $P$ is that atom which is closest to the surface of the - pole. To get into the proper position the molecule has to rotate by $180^{\circ}$ to $\left(^{(+)} X-P^{(-)}\right)$in order to re-position hydrogen $X$ onto the surface of the - pole. These rotations apply to all molecules in the chain. Grotthuß' did not mention this necessity. Faraday pointed to this fact when he explained that ice as ordinary insulating dielectric cannot be electrolyzed, whereas liquid water can (Experimental Researches in Electricity - Fourteenth Series, 1839; 1705. ${ }^{[73],[74]}$
}

"Physisch-chemische Forschungen" Grotthuß wrote somewhat embittered (ref. ${ }^{[75]}$, pp. 113-115):

"Meine (...) Theorie ist später von Davy (...). und von Berzelius (...) ohne meiner zu gedenken, weiter verbreitet und (...) jetzt von allen Chemikern (...) angenommen worden; nur muß ich bedauern, daß viele von ihnen, wiewohl fälschlich, nicht mir, sondern den beiden letztgenannten Chemikern diese Theorie zuschreiben die ich jedoch weit früher aufgestellt (...) habe ${ }^{42},(.$.$) Nachfol-$ gender Aufsatz wurde von mir 1805 in Neapel entworfen, und noch in demselben Jahre in Rom gedruckt. (...) daß diese Grundidee von mir ein ganzes Jahr (...) früher als Davy (...) aufgestellt worden ist, brauch ich wohl kaum noch hinzuzufügen. Diesen 1805 in Rom in französischer Sprache gedruckten Aufsatz $\mathrm{z}^{43}$ sandte ich an Fourcroy nach Paris und dieser ließ ihn einige Monate später nämlich im April 1806 in den Annales de Chimie aufs neue abdrucken, ${ }^{44}$ Davys obenangeführte Abhandlung betreffend, über einige chemische Wirkungen der Electricität wurde erst am 20. November 1806 von ihm in der königl. Gesellschaft zu London vorgelesen und erschien erst 1807 in den Transact. philos. ${ }^{45}$ gedruckt." (My (...) theory was later disseminated by Davy (...) and Berzelius (...) without further commemorating me, and is now accepted (...) by all chemists; but I must regret that many of them, albeit falsely, attribute this theory not to me, but to the latter two chemists, though I have it established much earlier, (...) The following essay was drafted by me in Naples in 1805, and printed in Rome the same year (...). I hardly need to add that this basic idea was put forward by me a whole year (...) earlier than Davy. I sent this essay, printed in French in 1805 in Rome, (...) to Fourcroy in Paris, and a few months later, in April 1806, he reprinted it anew in the Annales de Chimie. Davy's above-mentioned essay about some chemical effects of electricity was read only on November 20, 1806 by him at the Royal Society in London and appeared printed not until 1807 in the Transact. philos.). [Citations added by the author].

In this complaint Grotthuß referred to Davy's celebrated Bakerian lecture, ${ }^{46}$ read on November 20, 1806, entitled "On Some Chemical Agencies of Electricity" (ref. ${ }^{[62]}$, p.29).

Yet in Chapter I of Grotthuss' aforementioned paper $^{[67]}$ the subject was the "Action of Galvanic Electricity upon certain Bodies dissolved in Water", p. 330-334 in the English version $\left.{ }^{[66]}\right)$. In this theory, "metallic" solutions ${ }^{47}$

\footnotetext{
${ }^{42}$ See e.g. ref. ${ }^{[76]}$, p. 691.

${ }^{43}$ See ref. ${ }^{665]}$

${ }^{44}$ See ref. ${ }^{[67]}$.

${ }^{45}$ Ref. ${ }^{[62]}$.

${ }^{46}$ The Bakerian Medal and Lecture is awarded annually by the Royal Society and was established in 1775 by Henry Baker. Humphry Davy was awarded the medal every year between 1806 and 1811, and then in 1826.

${ }^{47}$ Meant were solutions of metal salts or metal oxides.
} 
form a chain of charged particles in the same way as water, which move electrophoretically towards their respective electrodes. Grotthuß wrote (on p. 338 of ref. ${ }^{[66]}$ )

\begin{abstract}
"XXIV. The polar arrangement, such as exists in the elementary molecules of water traversed by the Galvanic current, ought to be established equally among the elementary molecules of every other liquid body, provided they are solicited by the same forces. In the metallic solutions the electric polarity takes place among the elements of the oxide, the oxygen of which passes to the positive pole, and the metal of it is deposited at the negative pole."
\end{abstract}

Grotthuß observed that with certain salts "the molecules of the metal in solution are revived, assuming a symmetrical arrangement, which extends in the direction of the galvanic current." This symmetrical arrangement mimicked the shape of leaves of ferns, or of trees with limbs and twigs; its generation was therefore named arborisation. ${ }^{48}$ The metal trees grew continuously larger at the negative pole, but hydrogen was never formed as gas there during the galvanic action. Quite remarkably, Grotthuß stated that the arboreal growth from the negative toward the positive pole was always in the direction of the current. He took this fact as evidence of the correctness of his theory regarding water which he described in Chapter II of his paper.

\subsection{November 1806: Humphry Davy's Bakerian Lectures, catalysts for resurgence of research in galvanic electricity in Britain after a four-years hiatus}

After a gap of four years since his last publications on galvanic electricity in 1802, Humphry Davy presented the results of his recent investigations in his celebrated Bakerian lectures, read November, 1806, ${ }^{49[62]}$ and November, 1807. ${ }^{[78]}$ Davy reported the results of his numerous elaborate experiments with galvanic electricity under various experimental conditions, and with a large number of compounds. With respect to the action of the galvanic electricity on water Davy presumed (in the same manner as Grotthuß) that the constituents of water, hydrogen and oxygen, are positively and nega-

\footnotetext{
${ }^{48}$ Arborisation of metals without electricity had already been executed by alchemists. By galvanic electricity it was described first in 1800 by Cruickshank with silver trees (arbor Dianae), ${ }^{[11]}$. in 1800 by Brugnatelli (published in Annali di Chimica, 1800, T. XVIII, p. 136; excerpt in ref. ${ }^{[45]}$, in 1801 by Gruner as dendrites of silver from silver salt solutions (ref. ${ }^{[37]}$, pp. 216-227.) and in 1805 by Ritter as tree of lead dendrites. ${ }^{[77]}$

${ }^{49}$ It was the same Bakerian lecture that was discussed in the previous Section, which dealt with the decomposition of water; now the focus is to that of salts, acids and bases. ${ }^{[62]}$
}

tively polarized (electropositive and electronegative), and form a conducting chain. Davy assumed that upon completing the electric circuit oxygen and hydrogen are attracted by or repelled from the electrified metallic surfaces of the oppositely charged poles, and the electric forces follow the action at a distance. Water is split into its elements when its chemical affinity in the molecule is overcome by electrical forces. The energies of the particles which are electrophoretically moving are transferred from one particle to the "immediate neighboring particle of the same kind", which causes the rows of both elements to move towards their respective poles. At this point, note that each relocated particle is immediately substituted by that behind, and the water remains unchanged within the internal volume. This brings Davy to the point to state

"In the cases of the separation of the constituents of water, (....) forming the whole of the chain, there may possibly be a succession of decompositions and recompositions throughout the fluid."

and he continued, referring to a neutral point, which is characteristic for the action at a distance

"It is easy to explain, from the general phenomena of decomposition and transfer, the mode in which oxygene and hydrogene are separately evolved from water. The oxygene of a portion of water is attracted by the positive surface, at the same time that the other constituent part, the hydrogene is repelled by it; and the opposite process takes place at the negative surface; and in the middle or neutral point of the circuit, whether there be a series of decompositions and recompositions, or whether the particles from the extreme points only are active, there must be a new combination of the repelled matter."

Davy also wondered whether the particles of the salts can pass from the one to the opposite pole through different "menstrua", even when they possess a stronger attraction to them. An example of an experimental arrangement for this question is shown in Figure 6.

In one of these experiments Davy filled dissolved muriate of barytes ${ }^{50}$ into tube $A$ with the positive, and distilled water into tube $B$ with the negative pole. First he poured muriatic and nitric acid, respectively, into the middle tube. Once the circuit was closed, the barytes, like most other alkaline substances, passed through the acids without any problems, and were transmitted to tube $B$ with the negative wire. Vice versa, these acids

\footnotetext{
${ }^{50}$ Barytes, a term which dates back to late 18th century, is a mineral which consists of barium sulphate. In the main text muriate of barytes means barium chloride. Muriatic acid is hydrochloric acid.
} 


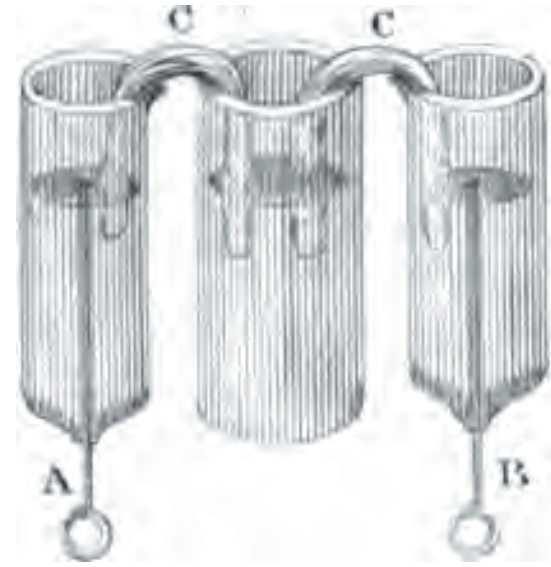

Figure 6. Drawing of Davy's experimental arrangement for the study "On the Passage of Acids, Alkalies, and other Substances through various attracting chemical Menstrua, by Means of Electricity". It shows three glass tubes with platinum wires as poles in the two outer tubes $A$ and $B$, which communicate with the middle tube by strips of amianthus $C$ (i.e. a fine silky asbestos), wetted with distilled water. The experiments are described in the text. It clearly confirms the migration of ions by electrophoresis. Taken from ref. ${ }^{[79]}$.

passed trouble-free electrophoretically through aqueous solutions of barytes. ${ }^{51}$ However, attempts to pass barytes when sulphuric acid was inserted into the middle tube gave a completely different result: after closing the circuit, barytes could not be found in the distilled water in tube $B$, but sulphate of baryte precipitated in the middle tube. The same effect was observed when a solution of sulphate of potash ${ }^{52}$ was in tube $B$ with the negative pole of the circuit, a saturated solution of barytes in the middle tube, and distilled water in that with the positive pole. In this case sulphuric acid could not be found in distilled water in tube $A$ after closing the circuit, but again sulphate of baryte precipitated in the intermediate tube. Due to its insolubility, in both cases this salt became excluded from the galvanic action, inhibiting the further transmission of baryte to the negative, and of sulphate to the positive pole as consequence. This result was clear evidence that the electrophoretic current is due to the migration of ions through the solution, and is an important finding for the subject at hand.

Davy summarized his observations in section " $v i$. Some general Observations on these Phenomena, and on the Mode of Decomposition and Transition" commencing

\footnotetext{
${ }^{51}$ Note that barium chloride and nitrate are well soluble in water, in contrast to the sparingly soluble sulphate.

${ }^{52}$ Potash is a mixture of water soluble potassium compounds and potassium-containing materials; its main component is potassium carbonate. In the present context sulphate of potash stands for potassium sulphate.
}

with the repetition of the known facts (pp. 28, 29)

"...that hydrogene, the alkaline substances, the metals, and certain metallic oxides, are attracted by negatively electrified metallic surfaces, and repelled by positively electrified metallic surfaces; and contrariwise, that oxygene and acid substances are attracted by positively electrified metallic surfaces, and repelled by negatively electrified metallic surfaces; and these attractive and repulsive forces are sufficiently energetic to destroy or suspend the usual operation of elective affinity."

In an attempt to generalize the theory that he had put forward about the electrolysis of water and the simultaneous electrophoresis of the ions he continued

\footnotetext{
"It is very natural to suppose, that the repellent and attractive energies are communicated from one particle to another particle of the same kind, so as to establish a conducting chain in the fluid; and that the locomotion takes place in consequence; ..."
}

and he expressed (see Figure 7 and its Legend) that

"solutions of neutral salts forming the whole of the chain, there may possibly be a succession of decompositions and recompositions throughout the fluid."

\subsection{Theories as of 1807 at the European Continent}

In France the chemist Jean René Denis Riffault (1752 - 1826) and the physicist and mathematician Nicolas Maurice Chompré (1750 - 1825) published in 1807, too, a theory about the transition of electricity in solutions of acids or bases. They hypothesized that two simultaneous currents fragment the bodies into their elements throughout the solution and not only at the poles. They assumed that the flow of the negative electricity collects the acids and transports them to the positive pole, and the same happens vice versa with the bases. In their opinion the currents were the stronger the closer they were to their respective poles. ${ }^{[82,83]}$

Jean-Baptiste Biot, the French physician, mathematician, and astronomer, described his somewhat complex theory in 1824 in Chapitre XVII. Effets chimiques de l'Appareil voltaïque. pp. 628-651 of his book Précis Élémentaire de Physique Expérimentale. ${ }^{[84]}$ Biot assumed that the decomposable substance possesses opposite electrical states close to the two poles. The fluid is most positive at the positive pole, from where its positive polarity decreases with increasing distance, and reaches neutrality at the indifference point in the middle between the poles. From here on, it approaches the neg- 


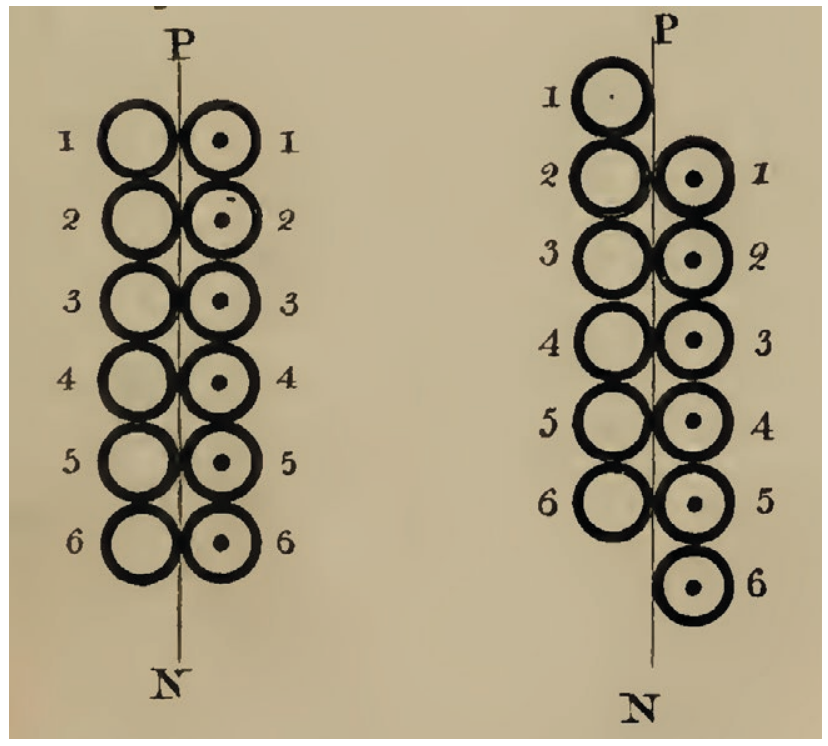

Figure 7. Illustration of Davy's theory of the electrophoretic migration of the oppositely charged particles of a neutral salt during electrolysis. $\mathrm{P}, \mathrm{N}$ : positive and negative poles. $\odot, \bigcirc$ : positiv and negativ particles of the neutral salt $\bigcirc \odot$, which forms a conducting chain in the solution. Left and right pictures: arrangement prior and after closing the circuit. See the main text for details and footnote ${ }^{53}$ for author's comment. Taken from ref. ${ }^{[80]}$. Nearly the same scheme is depicted by Berzelius to illustrate his similar theory in ref. ${ }^{[81]}, \mathrm{p}$. 278.

ative pole and becomes increasingly negative. When a salt particle is disassembled at the negative pole, its acid part becomes more negative than the undecomposed ones. It is thereby repelled from the pole and increasingly attracted by the positive pole and by the particles of the undecomposed positive fluid around this pole. In contrast to Davy, Biot assumed that the particle is attached to electricity for the duration of the transition and is therefore drawn to the pole with the opposite charge. Thus, decomposition of the particles happens in the portions of the solution close to the poles, but not between them.

The Swiss chemist Auguste Arthur de la Rive (1801, Geneva - 1873, Marseille) published in 1825 a theory that dismissed Grotthuß' and Davy's concepts of electrophoretic motion through decomposition and recombination. ${ }^{[85]}$ de la Rive assumed a combination

\footnotetext{
${ }^{53}$ Comment of the author: This configuration will most likely not form a stable chain because the particles $\odot$ and $\bigcirc$ in the vertical rows are in direct contact with those of like charge. In addition, the molecules would not be arranged parallel in the chain and thus not perpendicular to the current, but would rotate alternately by $90^{\circ}$ and form a chain that is arranged as ... $\odot \odot \odot \odot \bigcirc \ldots$... The same applies for Berzelius' theory, but not for Grotthuß'.
}

of the decomposed bodies with the electricity which is released from respective poles. Concerning water, the electricity from the positive pole unites accordingly with the hydrogen, moves to the negative pole where it is decomposed into electricity and hydrogen, which is set free as gas. An analogue process takes place with the electrified oxygen, which travels from the negative pole to the positive one. In contrast to Grotthuß' and Davy's theories, in that of de la Rive the successive decomposition and recompositions in the course of the current does not occur. Decomposition of the particles happens only at the poles, but no recomposition follows.

For completeness we mention the French mathematician Jean Nicolas Pierre Hachette (1769, Mézières 1834, Paris). In 1832, in the same year Michael Faraday presented his First Series of Experimental Researches in Electricity, ${ }^{\left[{ }^{[6]}\right.}$ Hachette assumed the successive decomposition of water by a magneto-electric current. ${ }^{[87,88]}$. However, he did not discuss the migration of the decomposed parts. He concluded (ref. ${ }^{[87]}$, p. 73)

“Il résulte de cette experience, $1^{\circ}$ qu'il n'est pas nécessaire, comme on le croyait, que l'action des deux électricités positive et négative, soit simultanée pour la décomposition chimique de l'eau; $2^{\circ}$ que l'action, dont la discontinuité n'est qu'instantanée, peut aussi produire cette décomposition." (It results from this experiment, $1^{\circ}$, that it is not necessary, as it was believed, that the action of the two electricities, positive and negative, be simultaneous for the chemical decomposition of water; $2^{\circ}$ that the action, the discontinuity of which is only instantaneous, can also produce this decomposition.)

In any case, taking the various theories into account, it is remarkable how long Grotthuß' from 1805 lasted. Notwithstanding its replacement by Rudolf Clausius' much better-founded theory in $1857,{ }^{[89-91]}$ Clausius' theory - which will be discussed in the subsequent Part 3 of this series - was acknowledged, but largely ignored; and that of Grotthuß was accepted almost unchanged for eight decades.

Although Grotthuß' theory is rather a subject of the history of electrochemistry, his name is still connected at present time to the special mechanism of the electrophoretic transport of $\mathrm{H}^{+}$in aqueous solutions (named proton-jumping or proton-hopping). This Grotthußmechanism explains the extraordinarily high ion conductivity and ionic mobility of $\mathrm{H}^{+}$due to the presence of clusters of water molecules and their involvement in $\mathrm{H}^{+}$ transfer (see e.g. ref. ${ }^{[92]}$ ). 


\section{AS OF 1832: MICHAEL FARADAY'S POINEERING CONTRIBUTIONS IN ELECTRICITY}

Michael Faraday ${ }^{54}$, having attended only elementary school was given by a fortunate coincidence and on his own initiative the position as Sir Humphry Davy's laboratory assistant in March 1813. This was the beginning of his outstanding career.

At first he assisted Davy with chemical experiments, and was allowed to carry out some by himself. ${ }^{55}$ In 1820 he was fascinated by the discovery of electromagnetism by Hans Christian Ørsted ${ }^{56,[99]}$ and began research in this new field, concurrently to his chemical work on organic compounds. In autumn of 1821 he discovered the electro-magnetic rotation. ${ }^{[100]}$ During 1824 and 1826 he attempted, to "convert magnetism into electricity", but without success. ${ }^{[101]}$ After a break until 1831 he returned to investigate electromagnetic phenomena and to electricity. In this year he made the important discovery of the electromagnetic induction. ${ }^{[86]}$

\subsection{Faraday's Series of "Experimental Researches in Elec- tricity"}

From 1832 to 1834 Faraday published eight comprehensive papers of the series entitled "Experimental Researches in Electricity". In this series Faraday communicated the results of his pioneering research on electromagnetism, magneto-electric induction, electricity and electrolysis in Phil. Trans. ${ }^{[10,86,102-107]}$ After his investigations of electromagnetism in 1831 and 1832 he focused his research on electrical and electrochemical topics. The "new law of electric conduction" was published in 1833 in the Fourth Series of Experimental Researches in Electricity, ${ }^{[104,108]}$ and aroused his interest in electrochemical decomposition. Although Faraday is better known

\footnotetext{
${ }^{54}$ Michael Faraday was born in 1791 in Newington Butts, now part of London, and died in 1867. Instead of going into details of Faraday's biography, We refer to a recently published paper by F. Bagnoli and R. Livi in this journal. ${ }^{[93]}$. In their publication the scientific focus is not on the migration of ions by electrophoresis. We have avoided duplicating information, although in some cases it was is inevitable, for example in definitions or in verbatim reproductions of Faraday's statements.

${ }^{55}$ Faraday's first scientific publication which he was allowed to publish as laboratory assistant by his own name was about "Analysis of the native caustic Lime" and appeared in 1816 in Vol. I of The Journal of the Science and of the Arts, later named The Quarterly Journal of Science, Literature, and the Arts. ${ }^{[94]}$. The subsequent experiments dealt especially with compounds from chlorine and carbon, and the isolation of "bi-carburate of hydogen" (i.e. benzene) and other arenes (see e.g. refs. $[95],[96],[97],[98])$.

${ }^{56}$ Hans Christian Ørsted (in German Hans Christian Oersted; 1777, Rodkøbing - 1851, Copenhagen) was a Danish physicist, chemist and nature-philosopher. He was a friend of Johann Wilhelm Ritter.
}

for his work on electrolysis - where he derived the laws named after him - his theories about the motion of ions, which superseded those put forward so far, cannot be emphasized enough. Hence, Faraday evaluated and criticized these theories in the Fifth Series, ${ }^{[105,109]} \$ 11$. On Electro-chemical Decomposition, read June 20, 1833, 481. - 491. ${ }^{57}$, and presented his own conclusions.

That being said, Faraday published numerous important contributions in many scientific fields, but in this review only those will be discussed which had a closer connection to the present topic. It is mentioned that these contributions do not necessarily follow a chronologic order in this text. They are, nevertheless, dealing with the migration of ions in solution in direction of lines of electric force, in accordance with the definition of electrophoresis given above. Note that Faraday coined two new key terms (in the previous sentence marked in Italic): ion and lines of electric force. We take thus the occasion to begin with Faraday's proposal of a new, unified terminology, which replaced the earlier less systematic one, und will end this review with Faraday's groundbreaking theory of the lines of electric force, also the electric lines of force, the basis of James Clerk Maxwell's field theory.

\subsubsection{Faraday`s recommendation for a defined terminology}

In the preliminary of his Bakerian lecture in which Faraday summarized his results in the Seventh Series ${ }^{[10]}$ he pointed to the confusing and arbitrary denotations applied thus far in electro-decomposition issues and recommended their replacement by a consistent and well-defined terminology. ${ }^{58}$ For this purpose, he suggested to use artificial words, constructs of ancient Greece words, viz. by replacing the term pole by electrode, and to distinguish between anode and cathode. He also suggested the terms ion, anion, cation, electrolyte, electrode, and electrolyze. ${ }^{59}$

\footnotetext{
${ }^{57}$ The numbers, here 481. and 491., are those of the sub-sections of the paragraphs which subdivide the entire Series.

${ }^{58}$ Although Berzelius opposed against it, meaning: "Faraday glaubt, ... daß unsere gewöhnlichen Wissenschafts - Benennungen ... unzureichend werden; daher hat er andere eingeführt, von denen ich aber nicht glau$b e$, weder daß sie in irgend einer Hinsicht nothwendig waren, noch daß sie befolgt zu werden verdienen." (ref. ${ }^{[110]}$, pp. 37,38) (Faraday believes ... that our common scientific designations ... are becoming inadequate; hence he introduced others, but I do not believe that they were necessary in any way or that they deserve to be obeyed.)

${ }^{59}$ One might wonder about the reason why Faraday did not introduce the term electrophoresis (greek act of bearing", means thus "the act of bearing electricity"). Probably he avoided its use because the simple and common device for the generation of electricity, the "electrophorus" was still widely known since Volt's time (see Part 1 of this series). ${ }^{[1]}$. But the author must confess that he did not search for an according text passage, neither in the six
} 
Since the historical background of the creation of this new terms was already briefly discussed in a previous issue of this journal, ${ }^{[93]}$ we will not go further into the details of their origin. Yet, it is remarkable that it is still standard nomenclature even today, about two centuries after Faraday's recommendation.

3.1.2 The inextricable connection of electrolysis and the electrophoretic current

A central point in Faraday's theories was the cooccurrence of electrolysis and the electrophoretic current. He considered the two phenomena as being so inseparable, "that one cannot happen without the other". The importance of this connection for Faraday becomes clear as he repeated his conviction in various formulations (see $₫ 13$ of the Seventh Series, ${ }^{[10]}$ and the Eighth Series ${ }^{[107]}$, p. 436), which read, for example

"854. On the other hand, the relation between the conduction of the electricity and the decomposition of the water is so close, that one cannot take place without the other. ...

855. Considering this close and twofold relation, namely, that without decomposition transmission of electricity does not occur......

858. Those bodies which, being interposed between the metals of the voltaic pile, render it active, are all of them electrolytes (476.); and it cannot but press upon the attention of every one engaged in considering this subject, that in those bodies (so essential to the pile) decomposition and the transmission of a current are so intimately connected, that one cannot happen without the other....

923. ... An electrolyte is always a compound body: it can conduct, but only whilst decomposing. Its conduction depends upon its decomposition and the transmission of its particles in directions parallel to the current; and so intimate is this connexion, that if their transition be stopped, the current is stopped also; if their course be changed, its course and direction changes with them; ..."

In these statements the flow of charge carried by ions is phrased as "conduction of electricity, transmission of electricity, transmission of a current, transmission of its particles, transition [of particles]", all of which express what we name the electrophoretic current.

3.1.3 1833/1834: Faraday's theory of the electrophoretic migration of the ions during electrolysis, and his seminal concept of the lines of force

volumes of Faraday's correspondence, ${ }^{[111]}$. nor in the seven volumes of his diary (the "Experimental Notes"). ${ }^{[112]}$
The part following the preliminary in the aforesaid Seventh Series in $1834^{[10]}$ can be seen as the focus of his point of view at the motion of ions in solution during electrolysis. In this part Faraday reported his experiments of the relation between current and electrochemically decomposed matter, what he already did in the Fifth Series in 1833. ${ }^{[105]}$ One might ask how this relation can contribute to the problem of the migration velocity of an ion; we detail it as follows.

With reference to the previous theories, the velocity of migration is determined by the electrical forces that act on the ion by the action at a distance. In this case, the electric forces and therefore the migration velocity are not constant but vary with the distance between ion and electrodes. We recall that electricity was throughout considered as a fluid. Over the course of his research, Faraday began to doubt these previous theories about the continuous character of electricity and the action at a distance. It was his unparalleled merit, thanks to his studies of electricity and magnetism, to open the window for a new look at the migration velocity of ions.

3.1.4 The absolute quantity of electricity, a consequence of the law of definite electrochemical action

In the Fifth Series Faraday argued "505. That for a constant quantity of electricity, whatever the decomposing conductor may be, ... the amount of electro-chemical action is also a constant quantity, i.e. would always be equivalent to a standard chemical effect founded upon ordinary chemical affinity". In the Seventh Series ${ }^{[10]}$ in 1834 he presented as conclusion which he derived from the quantitative measurements of numerous electrolytically decomposed electrolytes the "law of definite electrochemical action", or the "law of the definite chemical action of electricity" (807.) which he expressed in different phrasing, for example as

"732. ... with respect to water, that when subjected to the influence of the electric current, a quantity of it is decomposed exactly proportionate to the quantity of electricity which has passed,...

783. The law was expressed thus: The chemical power of a current of electricity is in direct proportion to the absolute quantity of electricity which passes.

810. ...the results prove that the quantities so decomposed are perfectly definite and proportionate to the quantity of electricity which has passed.

836. Electro-chemical equivalents coincide, and are the same, with ordinary chemical equivalents."

Note that Faraday accentuated the quantity of electricity, not its intensity, what he already did in the Third Series (ref. ${ }^{[103]}, 329$.). 
The forecited extension to quantitative experiments enabled Faraday to show that the law of definite electrochemical action is generally valid. The electrochemical equivalent is a property of a particular ionic species (see section vii of the Seventh Series, "On the definite nature and extent of Electrochemical Decomposition"). ${ }^{[10]} \mathrm{He}$ explained that the anions and the cations of an electrolyte decompose in portions of electrochemical equivalents, that is to say, in quantities which are given by their atomic weigh divided by their charge number. Thus, the electrochemical equivalent weight of hydrogen is 1 , that of oxygen is $16 / 2=8$, etc. (p. 111).

Because of the law of definite electrochemical action Faraday came to his fundamental conclusion that "an absolute quantity of electricity associated with the particles or atoms of matter" exists (\$13). He wrote

" 852 . The theory of definite electrolytical or electro-chemical action appears to me to touch immediately upon the absolute quantity of electricity or electric power belonging to different bodies. ..., yet there is an immensity of facts which justify us in believing that the atoms of matter are in someway endowed or associated with electrical powers, to which they owe their most striking qualities, and amongst them their mutual chemical affinity."

From this insight Faraday derived that electricity consists of fundamental quantities. Ions are therefore always charged by one or integer multiples of this charge unit. ${ }^{60}$

\subsubsection{Faraday`s rejection of the action at a distance}

Faraday contradicted especially the established concept of the action at a distance, the inverse square law. One might remember that Grotthuß formulated in $\$$. 18 . of his original paper from $1805^{[65]}$ this action at a distance concept in regard of the transport of the charged particles in water as follows:

“\$. 18. L'action de chaque force par rapport à une molécule d'eau située sur la route du courant galvanque, est en raison inverse du quarré de la distance à laquelle elle s' exerce." ${ }^{1}$

\footnotetext{
${ }^{60}$ It may appear questionable to the reader that we are discussing properties that seem to be only relevant in electrolysis. However, since the migration velocity of an ion depends on its charge, the findings just discussed are of outmost importance for electrophoresis.

${ }^{61}$ Grotthuß' own translation into German in his book from 1820 reads: "\$. 18. Der Einfluß einer jeden Kraft hinsichtlich auf ein Teilchen Wassers, welches in der Richtung des galvanischen Stromes liegt; wirkt umgekehrt wie das Quadrat der Entfernung in welcher sie sich äussert" (ref. [28], p. 122). In the English version published in Phil. Mag. it was translated as: "XVIII. The action of each force, in respect to a molecule of water situated in the direction of the Galvanic current, is in the inverse ratio of the square of the distance to which it exercises its influence." (ref. ${ }^{[66]}$, p. 335).
}

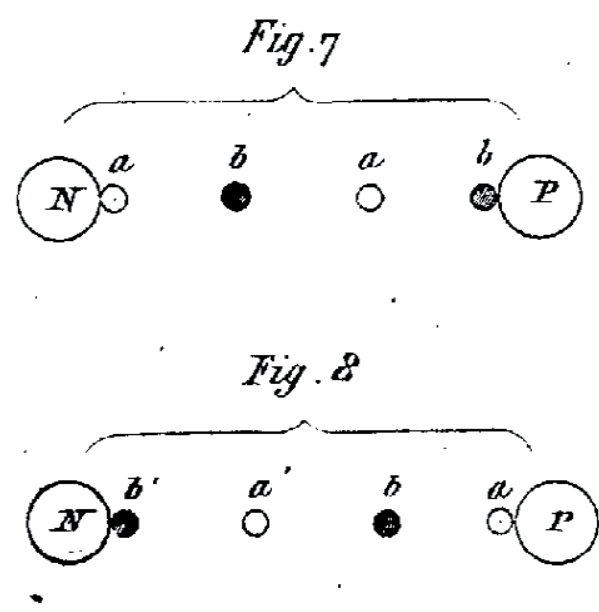

Figure 8. Drawing which illustrates Michael Faraday's concept of the electrophoretic migration of the ions during electrolysis. In the upper scheme anions $a$ and $a^{\prime}$ migrate towards the anode, $P$, cations $b$ and $b^{\prime}$ to the cathode, $N$. They are moving parallel to the lines of forces, which fill the space between the two electrodes. For details, see main text, quoted sub-section 519. in Faraday's Fifth Series. Taken from ref. ${ }^{109}$.

From his magneto-electric investigations Faraday realized that this action at a distance does not apply, and this previous concept was false. Fortuitously, this part of Grotthuß' theory was already withdrawn by himself in 1820, about one decade prior to Faraday's criticism. Most probably Faraday did not have knowledge of Grotthuß' comments in the German translation of his article, which he published in his book "Physisch-chemische Forschungen" (this book is quoted above) ${ }^{[28]}$. Grotthuß added (in $\S .18$, p.122)

"Die Annahme daß die Polarelectricität (Galvanismus) umgekehrt wie das Quadrat der Entfemung wirke, ist grundlos und nicht einmal ganz zuverlässig für die gewöhnliche Electricität erwiesen (M, s. Simon im 28sten Bde. von Gilberts Annalen ${ }^{62}$ ). Daher hätte dieser Paragraph füglich wegbleiben können." (The assumption that the polar electricity (galvanism) is inverse of the square of the distance is proved groundless and not even completely reliable for the ordinary electricity $(\mathrm{M}$, see Simon in the 28th volume of Gilbert's Annals). Therefore, this paragraph could have stayed off.)

\subsubsection{The migration of ions and the electric lines of force}

Already in the Fifth Series, $₫ 11$, iii., "Theory of Electrochemical Decomposition", ${ }^{[105]}$ read a few months prior

${ }^{62}$ Ref. ${ }^{[113]}$, specified by the author. 
to the Seventh Series, ${ }^{[10]}$ Faraday described his view at the migration of ions. In his opinion, "the two elementary electric currents, moving in opposite directions, from pole to pole, constitute the ordinary voltaic current." 63 He stated that the influence that is present in the electric current has to be strictly devised as "an axis of power having contrary forces, exactly equal in amount, in contrary directions." (517.). This theory was in clear contradiction to the earlier established concept of the action at a distance and the point of indifference or neutrality and marked a fundamental change in the principles of ion migration.

Faraday considered the decomposing bodies as a mass of particles, which contribute to the final effect given that they are in the course of the electric current. The effect of the electrochemical decomposition is based on an internal corpuscular action, which originates from a force, that either adds to the common chemical affinity, or determines its direction. The combining particles pass in opposite directions because the usual chemical affinity is reduced, weakened or partially neutralized by the influence of the electric current in one direction parallel to its course, and reinforced or supplemented in the opposite direction. The author comments that this is in fact the description of the electrophoretic motion.

Faraday expounded his theory again in section 519. of the Fifth Series (ref. ${ }^{[105]}$, p. 696, German translation ref. ${ }^{[109]}$ ) explaining (see Figure 8). ${ }^{64}$

"519. In this view the effect is considered as essentially dependent upon the mutual chemical affinity of the particles of opposite kinds. Particles $a$ a, fig. 7, could not be transferred or travel from one pole $N$ towards the other $P$, unless they found particles of the opposite kind $b b$, ready to pass in the contrary direction: for it is by virtue of their increased affinity for those particles, combined with their diminished affinity for such as are behind them in their course, that they are urged forward: and when any one particle $a$, fig. 8 , arrives at the pole, it is excluded or set free, because the particle $b$ of the opposite kind, with which it was the moment before in combination, has, under the superinducing influence of the current, a greater attraction for the particle $a^{\prime}$, which is before it in its course, than for the particle $a$, towards which its affinity has been weakened."

Consequently, all composite particles in the course of the current act conjointly, except those which are in con-

\footnotetext{
${ }^{63}$ This attribution deviates from ours, because the ordinary voltaic current is the flow of electrons (electrons were unknown at the time). In contrast, "the two elementary electrical currents that move from pole to pole in opposite directions" is the flow of charge carried by ions in solution. It is the current for which we coined the term electrophoretic current.

${ }^{64}$ The collection of all 14 Series of the Experimental Researches in Electricity, reprinted from the Phil. Trans. of $1831-1838$ is published in ref. ${ }^{[73]}$.
}

tact with the poles. They "consist of elementary particles, which, whilst they are in one direction expelling, are in the other being expelled". The acting particles (i.e. the ions) which represent the electric current move in direction of the electric lines of action or lines of electric force. Like the lines of magnetic force ${ }^{65}$ the electric lines do not necessarily form a straight line between the electrodes, neither must they be parallel, but they do not cross. ${ }^{66}$

Due to its importance, we repeat the explanation of the line of force which Faraday gave about one decade later, viz. in the Nineteenth Series, read in November 1845. ${ }^{[14]}$ He stated

":- thus, by line of magnetic force, or magnetic line of force, or magnetic curve, I mean that exercise of magnetic force which is exerted in the lines usually called magnetic curves, and which equally exist as passing from or to magnetic poles, or forming concentric circles round an electric current. By line of electric force, I mean the force exerted in the lines joining two bodies, acting on each other according to the principles of static electric induction, which may also be either in curved or straight lines."

3.1.7 The migration velocity of the ions and its assumed context with the decomposition of equal chemical equivalents of anions and cations

Faraday's replacement of the earlier theory of the action at a distance by that of the electric lines of force ${ }^{67}$ and the conclusion of an elementary charge unit had farreaching consequences for the question of the migration velocity of the ions. In the earlier concept of the action at a distance this electric force acting on an ion varied with the in the inverse ratio of the square of the distance from the electrodes, and consequently its drift velocity varied as well. In Faraday's theory, the velocity in the electric field, in contrast, is constant during the motion of the ion along a field line. ${ }^{68}$ That is to say, in a homo-

\footnotetext{
${ }^{65}$ In the First Series of Experimental Researches in Electricity, read November 1831, Faraday reported the induction of electric currents and the generation of electricity from magnetism. In this paper, Faraday defined for the first time the lines of force as "By magnetic curves, I mean the lines of magnetic forces, however modified by the juxtaposition of poles, which would be depicted by iron filings; or those to which a very small magnetic needle would form a tangent."(ref. ${ }^{[86]}, 114$.; footnote at $\mathrm{p}$. 154). These magnetic field lines can be visualized by iron files poured onto a sheet of paper with a magnet underneath.

${ }^{66}$ All these properties apply for all configurations. In a homogeneous electric field, for example in the field between two plate electrodes, nearly all lines are straight and parallel, and, as all others in all configurations, are perpendicular to the surfaces of the plates.

${ }^{67}$ Ref. ${ }^{[114]}, 2149$., and ref. ${ }^{[115]}, 1662$.

${ }^{68}$ To emphasize the importance of Faraday's theory of the lines of electric force for electrophoresis, and his conclusion that ions carry elementary charge units, we skip a period in the development of the theory of
} 
geneous field ions migrate with an equal and constant velocity along the field lines that run parallel to one another. Faraday brought forward this argument in the Eighth Series read June $1834,{ }^{[107]}$ p. 448 , that

\begin{abstract}
"964. ... If any number of them [anions and cations] enter as ions into the constitution of electrolytes, and, forming one circuit, are simultaneously subject to one common current, the anions must move in accordance with each other in one direction, and the cations in the other. Nay, more than that, equivalent portions of these bodies must so advance in opposite directions; for the advance of every $32 \star 5$ parts of the zinc ... must be accompanied by a motion in the opposite direction of 8 parts of oxygen ... of 36 parts of chlorine ... of 126 parts of iodine ...; and in the same direction by electro-chemical equivalents of hydrogen, ... lead, copper and tin, ..."
\end{abstract}

It can be seen that Faraday based his conclusion on the opposite movement of equal electrochemical equivalents of cations and anions of an electrolyte to their respective electrodes during electrolysis. In the simplest case the electrolyte consists of two ions with a single charge each. Then, an anion cannot be oxidized on the anode unless a cation is reduced at the same time on the cathode. Due to the requirement to reach their electrodes at the same time Faraday concluded that the migration velocities of cations and anions must also be equal. Faraday did not provide any values for this velocity. On the top of that, it will be seen later that his hypothesis was based on a mistake in reasoning.

The first systematic attempts to measure the values of the drift velocity were made by Wilhelm Hittorf in the 1850s. Yet, Hittorf did not determine the absolute, but the relative velocities of the various ion species to one another, referred to as transference or transport numbers. This topic, and the subsequent studies to determine the actual migration velocity of an ion will be the subject of the following Part 3 of this historical retrospect.

ion migration. Today it is well-known that the electrical force acting on an ion is proportional to its charge, z.e, and the strength of the electric field, $E=U / d$. Here $z$ is the number of charges, $e$ the electron charge, $U$ the potential difference and $d$ the distance between the electrodes. That is, on ions with the same number of charges an equal electrical force is acting, independent of its distance from the electrodes. This is in clear contradiction to the action at a distance. This force accelerates the ion, but the oppositely directed frictional force of the medium increases with increasing speed. The frictional force depends on the size and shape of the ion and is thus different for different ions. When both forces are equal, the ion moves with a constant migration velocity (for the sake of simplicity, we have considered an ion at infinite dilution).

\section{SUMMARY}

By following the general definition that "electrophoresis is the motion of dispersed particles relative to a fluid under the influence of a spatially uniform electric field" we have chosen a probably unusual view at electrophoresis in this Part 2, since the focus is aimed exclusively at ions. This view is justified because, as defined above, ions of atomic or molecular size are also the subject of electrophoresis, not just colloidal particles as is conventionally considered.

Due to the inextricable linkage between ion migration and electrolysis the histories of these two phenomena are also intrinsically related. It is for this reason that this review begins with the year 1800 when electrolysis by galvanic electricity - which was considered as a fluid at that time - was discovered. It extends over the time until the 1830s and early 1840s when Michael Faraday superseded the previously established concept of action at a distance by that of the electric lines of force, which were later referred to as field lines of the electric field.

It is pointed out that during the electrolysis of decomposable compounds by galvanic electricity two kinds of currents can be differentiated in the closed electric circuit. The galvanic or voltaic current is the flow of charges carried by electrons in the metallic parts (electrons were not known at the time). But decomposition can only take place if an electric current flows through the liquid from one pole to the other. Although this process is obviously invisible to the naked eye, the several observations provided evidence that electricity was actually being transported through the liquid, e.g. due to the increased speed of electrolysis at higher concentrations of decomposable bodies, the analytic determination of parts of the decomposed molecules close to one pole, e.g. of potassium at the negatively charged electrode after electrolysis of muriate of potash, or by the kind of the decomposition products formed at the poles by electrolysis For this flow of these charged particles, later named ions, between the poles, which is an electric, but not a galvanic current, we coin the term electrophoretic current. While not common, it fully conforms to the definition of electrophoresis quoted above.

Taking these facts into account, the history of electrophoresis begins in 1800 with W. Nicholson's and A. Carlisle's experiments of decomposing water by the aid of a voltaic pile. Remarkably, just two months after their publication, as early as in September 1800, the first theories of the action of galvanic electricity on water were presented by W. Cruickshank in Britain and by J. W. Ritter in Germany. Both researchers hypothesized that gaseous hydrogen and oxygen, evolving at the separate poles, 
came from the same water molecule. In the following years, not surprising due to the novelty of the phenomena, experiments were carried out mainly for the acquirement of the results of galvanic action on solutions of arbitrarily chosen compounds and different experimental set-ups. In all cases the researchers were convinced that the two ions that assemble the decomposable molecule are tightly bound to each other, and could only be separated by the action of galvanic electricity, when the electric force from the connected voltaic pile overcame their chemical affinity. Davy and Berzelius assumed that the ions migrated because they were attracted or repelled by the charged poles, whereby the electric forces obeyed the action at a distance. That is, the forces decrease in the inverse ratio of to the square of the distance from the poles and cross at the point of indifference or neutrality. The compounds are decomposed near or at this point, but the decomposed particles appear at the poles, which makes this hypothesis quite difficult to comprehend. The action at a distance brought forth that the ions moved with varying, but not with constant velocity.

In 1803 Berzelius and W. Hisinger were able to create a classification based on the properties of the ions involved in electrolytic decomposition and the direction of their electrophoretic migration towards their respective poles. It was a first step to systematically categorize compounds into electropositive and electronegative classes.

Back in 1800, beginning with Cruickshank and Ritter, several other theories about the electrolytic decomposition and the electrophoretic current were developed. Works up to 1805 include the theory of the Italian L. V. Brugnatelli from 1800, who, to his surprise, found that the Belgian E.G. Robert (also Robertson and Robert-son) had already published almost the same theory before him; they report the theories of the French A. F. Fourcroy, L.-N. Vauquelin and L. J. Thénard in 1800 and 1801, of the German J. F. Erdmann in 1802, of H. Davy, who paused after 1802 for four years, and of the Swedes W. Hisinger and J. J. Berzelius in 1803.

However, one of the most plausible theories at that time, which surprisingly outlasted almost eight decades, was presented in 1805 by Theodor von Grotthuß (also C.J.T. de Grotthuss). He hypothesized that water or dissolved salts form a chain of polarized molecules, and only the terminal atoms of the chain, which were in direct contact with the surfaces of the oppositely charged electrodes were set free by galvanic electricity. However, important for electrophoresis is Grotthuß' hypothesis how the current flows through water or salt solutions. He assumed that the liberated terminal atoms are instantaneously replaced by the neighboring atoms of the same species, which led to a permanent decompo- sition and recombination of the molecules in the chain, and to the electric current in this way.

It was thus believed that free ions were never present in the fluid. To his disappointment, the priority of his theory was initially assigned to the widely recognized scientist Davy, who published a similar theory about one year later.

Indeed, in December, 1806 Davy read a celebrated Bakerian lecture with a theory in which he also assumed a chain of molecules, and a similar process of decomposition and recombination as Grotthuß. After Grotthuß and Davy, fewer theories were formulated, e.g. by the French J. R. D. Riffault and N. M. Chompré in 1807, and after a break of about fifteen years, by the French J.-B. Biot in 1824, then by the Swiss A. A. de la Rive in 1825 , and the French J. N. P. Hachette in 1832.

However, all these theories were dismissed in 1833 by Michael Faraday, who unambiguously rejected the concept of action at a distance. Based on his experience, which he had gained from his previous studies of magnetism and electromagnetism, Faraday developed the theory of lines of magnetic and electric force, which served James Clerk Maxwell for the mathematical formulation of the field theory. This was one of Faraday's groundbreaking contributions to the further development of electricity and electromagnetism and thus to electrophoresis as well and opened a new era in these topics. Another major contribution, which he deduced from his law of definite electrochemical action, was his proof that electricity consists of individual elementary charge units. The consequence of Faraday's seminal theories was that ions move at constant velocities parallel to the lines of the electric force that fill the space between the electrodes. Thus, after more than three decades the concept of the action at a distance and its consequences were superseded. What remained was the conviction that electrolyte molecules consist of tightly bound ions of opposite charge, which can only be separated by electrical forces, whereupon they are permanently and instantaneously decomposed and recombined forming in this way the electrophoretic current. Accordingly, free ions are not present in solutions in the absence of an electric field.

However, none of these theories dealt with the magnitudes of the velocities of ion migration, and the questions whether these speeds are actually equal, how high they are and on what conditions they depend, remained open.

\section{ACKNOWLEDGEMENT}

The author acknowledges Salvator Kenndler for his valuable comments. 


\section{REFERENCES}

[1] E. Kenndler, M. Minárik, Substantia 2021, 5, 119133.

[2] N. Gautherot, Ann. Chim. 1801, 39, 203-210.

[3] F. F. Reuss, Commentationes Societatis PhysicoMedicae, Apud Universitatem Literarum Caesaream Mosquensem Institutae, Moscow, 1807, p. xxxix.

[4] F. F. Reuss, (Reuß, Ferdinand Friedrich von), Mémoires de la Société Impériale des Naturalistes de Moscou 1809, 2, 327-337.

[5] IUPAC, Compendium of Chemical Terminology (the "Gold Book"). Compiled by A. D. McNaught and A. Wilkinson. electrophoresis., Blackwell Scientific Publications, Oxford, 1997.

[6] J. Lyklema, Fundamentals of Interface and Colloid Science. Vol. II: Solid-Liquid Interfaces, Vol. 2, Academic Press, London, San Diego, 1995.

[7] J. H. Lyklema, Substantia 2017, 1, 75-93.

[8] W. Nicholson, Ann. Phys. (Gilbert ed.) 1800, VI, 340-375.

[9] W. Nicholson, Nicholson's J. 1801, IV, 179-187.

[10] M. Faraday, Phil. Trans. 1834, 124, 77-122.

[11] W. Cruickshank, Nicholson's J. 1801, IV, 187-191.

[12] W. Cruickshank, Ann. Phys. (Gilbert ed.) 1801, VII, 99-102.

[13] A. A. Fisher, Doctoral thesis, University of Minnesota (Minnesota), 2010.

[14] W. Cruickshank, Nicholson's J. 1801, IV, 254-264.

[15] V. Becker, in Der Einbruch der Naturwissenschaft in die Medizin. Schriften der Mathematisch-naturwissenschaftlichen Klasse der Heidelberger Akademie der Wissenschaften, Vol. 20, Springer, Berlin, Heidelberg, 2008, p. 23.

[16] J. W. Ritter, Ann. Phys. (Gilbert ed.) 1801, 7, 409.

[17] J. W. Ritter, Neue Beyträge zur näheren Kenntnis des Galvanismus und Resultate seiner Untersuchung. Der Siderismus, Vol. 1/1, 1. ed., J. G. Cotta'schen Buchhandlung, Tübingen, 1808.

[18] J. W. Ritter, Der Siderismus. Campinetti, der königlich-baierischen Akademie der Wissenschaften vorgestellt, mit dem Antrag auf eine Commission zur Prüfung derselben; in einer General-Versammlung der königlichen Akademie, Vol. 1,1, J. G. Cotta, Tübingen, 1808.

[19] C. Amoretti, J. W. Ritter, Physikalisch und historische Untersuchungen über die Rabdomantie oder animalische Elektrometrie. Mit einigen ergänzenden Abhandlungen von J. W. Ritter, Vol. 1, Realschulbuchhandlung, Berlin, 1809.

[20] T. Dorn, Die Unglückseligen, Albrecht Knaus, Munich, 2016.
[21] H. Davy, Phil. Trans. 1826, 116, 383-422.

[22] J. W. Ritter, https://commons.wikimedia.org/wiki/ File:Ritter-Johann-Wilhelm-1804.jpg? uselang=de.

[23] J. W. Ritter, Ann. Phys. (Gilbert ed.) 1800, 6, 470471.

[24] J. W. Ritter, Ann. Pysik (Gilbert ed.) 1801, 9, 1-17.

[25] J. W. Ritter, Voigt's Magazin 1800, 2, 356-400.

[26] J. W. Ritter, Physisch-chemische Abhandlungen in chronologischer Folge, Vol. 1, C. H. Reclam, Leipzig, 1806.

[27] W. Babington, Nicholson's J. 1801, IV, 511-513.

[28] T. v. Grotthuß, Physisch-chemische Forschungen, Vol. 1, Johann Leonhard Schrag, Nürnberg, 1820.

[29] J. W. Ritter, Beyträge zur nähern Kenntniss des Galvanismus und der Resultate seiner Untersuchung, Vol. 2/1, Friedrich Frommann, Jena, 1805.

[30] J. W. Ritter, Ann. Phys. (Gilbert ed.) 1801, 9, 265352.

[31] H. Davy, Nicholson's J. 1801, IV, 275-281.

[32] H. Davy, Nicholson's J. 1801, IV, 326-328.

[33] H. Davy, Nicholson's J. 1801, IV, 394-402.

[34] C. W. Böckmann, Ann. Phys. (Gilbert ed.) 1801, 8, 137-162.

[35] L. A. v. Arnim, Ann. Pysik (Gilbert ed.) 1801, 9, 494-492.

[36] P. Erman, Ann. Phys. (Gilbert ed.) 1801, 8, 197215.

[37] W. J. L. Gruner, Ann. Phys. (Gilbert ed.) 1801, 8, 216-227.

[38] L. W. Gilbert, Ann. Phys. (Gilbert ed.) 1801, 8, 209-215.

[39] L. W. Gilbert, Ann. Phys. (Gilbert ed.) 1801, 8, 166-171.

[40] P. L. Simon, Ann. Phys. (Gilbert ed.) 1801, 8, 22-43.

[41] P. L. Simon, Ann. Phys. (Gilbert ed.) 1802, 10, 282300 .

[42] C. W. Pfaff, Ann. Phys. (Gilbert ed.) 1801, 7, 363367.

[43] P. Sue, Histoire du Galvanisme; et Analyse des differens ouvrages publiées sur cette découverte, depuis son origine jusqu'à ce jour, Vol. 2, 1 ed., Bernard, Paris, 1802.

[44] L. Brugnatelli, Annali di Chimica 1800, 18, 136.

[45] L. Brugnatelli, Ann. Phys. (Gilbert ed.) 1801, 8, 284-299.

[46] A. Volta, Ann. Phys. (Gilbert ed.) 1803, 14, 258265.

[47] E. G. Robertson, Ann. Chim. 1801, 37, 132-150.

[48] P. Sue, Histoire du Galvanisme; et Analyse des differens ouvrages publiées sur cette découverte, depuis 
son origine jusqu’à ce jour, Vol. 1, 2. ed., Bernard, Paris, 1805.

[49] E. G. Robertson, Mémoires: récréatifs, scientifiques et anecdotiques., Vol. 1, L'auteur \& Librairie de Wurtz, Paris, 1831.

[50] E. G. Robertson, Mémoires: récréatifs, scientifiques et anecdotiques., Vol. 2, L'auteur \& Librairie de Wurtz, Paris, 1833.

[51] E. Gilbert, Ann. Phys. (Gilbert ed.) 1804, XVI, $1-44$.

[52] E. Gilbert, Ann. Phys. (Gilbert ed.) 1804, XVI, 164220.

[53] E. Gilbert, Ann. Phys. (Gilbert ed.) 1804, XVI, 257290.

[54] J. F. Erdmann, Ann. Phys. (Gilbert ed.) 1803, 12, 450-457.

[55] J. F. Erdmann, Archiv med. Erfahrung (Horn ed.) 1804, VI, 126-190.

[56] J. F. Erdmann, Ann. Phys. (Gilbert ed.) 1802, 11, 211-220.

[57] W. Hisinger, J. J. Berzelius, N. Allg. J. Chem. (Gehlen ed.) 1803, 1, 115-149.

[58] W. Hisinger, J. J. Berzelius, Ann. Chim. 1804, 51, 167-174.

[59] I. Newton, Philosophice naturalis principia mathematica, 1. ed., S. Pepys, London, 1686.

[60] I. Newton, Newton's Principia. The Mathematical Principles of Natural Philosophy. By Sir Isaac Newton. Translated into English by Andrew Motte. To which is added, Newton's System of the World with a Life of the Author, by N. W. Chittenden, Vol. 1/2, Geo. P. Putnam, New York, 1850.

[61] C. A. de Coulomb, Mémoires sur lélectricité et le magnetisme. Extraits des Mémoires de l'Académie Royale des Sciences de Paris, publiés dans les années 1785 à 1789, avec planches et tableaux, 1. ed., Bachelier, Paris, 1785-1789.

[62] H. Davy, Phil. Trans. 1807, 97, 1-56.

[63] T. v. Grotthuß, Ann. Phys. (Gilbert ed.) 1819, 61, 50-74.

[64] J. A. Krikštopaitis, Nuova Voltiana: Studies on Volta and His Times, 2000.

[65] C. J. T. de Grotthuss, Mémoire sur la décomposition de l'eau et des corps qu'elle tient en dissolution à l'aide de l'électricité galvanique, Rome, 1805.

[66] C. I. T. de Grotthius, Phil. Mag. 1806, 25, 330-339.

[67] C. J. T. de Grotthuss, Ann. Chim. 1806, 58, 54-74.

[68] C. J. T. de Grotthuss, Ann. Chim. 1807, 63, 5-34.

[69] C. J. T. de Grotthuss, Nicholson's J. 1811, 28, 112125.

[70] T. v. Grotthuß, J. Phys. Chem. (Schweigger ed.) 1818, 20, 225-271.
[71] R. Pomès, Biochim. Biophys. Acta 2006, 1757, 871875.

[72] C. J. T. v. Grotthuß, J. Chem. Phys. Mineral. (Gehlen ed.) 1808, 5, 110-126.

[73] M. Faraday, Experimental Researches in Electricity. Reprinted from the Philosophical Transactions of 1831-1838, Vol. 2, Richard and John Edward Taylor, London, 1839.

[74] M. Faraday, Ann. Phys. Chem. (Poggendorff ed.) 1842, Erg. Bd. 1, 249-281.

[75] T. v. Grotthuß, in Physisch-chemische Forschungen, Vol. 1, Johann Leonhard Schrag, Nürnberg, 1820, pp. 115-126.

[76] M. H. Klaproth, F. Wolff, Supplemente zu dem chemischen Wörterbuche von Martin Heinrich Klaproth und Friedrich Wolff, Vol. 1 (A-E), Vossische Buchhandlung, Berlin, 1816.

[77] J. W. Ritter, N. Allg. J. Chem. (Gehlen ed.) 1805, 3, 692-699.

[78] H. Davy, Phil. Trans. 1808, 98.

[79] H. Davy, The collected works of Sir Humphry Davy. Vol. V. Bakerian Lectures and Miscellanious Papers from 1806-1815, Vol. V, 1. ed., Smith, Elder and Co. Cornhill, London, 1840.

[80] W. Henry, Manchester Memoirs 1813, 2, 293-312.

[81] J. J. Berzelius, J. Phys. Chim. 1811, 73, 253-286.

[82] J. R. D. Riffault, N. M. Chompré, Ann. Chim. $1807,63,77-88$.

[83] J. R. D. Riffault, N. M. Chompré, Ann. Phys. (Gilbert ed.) 1808, 28, 115-120.

[84] J.-B. Biot, Précis Élémentaire de Physique Expérimentale, Vol. 1, 3. ed., Deterville, Paris, 1824.

[85] A. A. de la Rive, Ann. Chim. Phys. 1825, 28, 190209.

[86] M. Faraday, Phil. Trans. 1832, 122, 125-162.

[87] J. N. P. Hachette, Ann. Chim. Phys. 1832, 51, 72-74.

[88] J. N. P. Hachette, Ann. Phys. Chem. (Poggendorff ed.) 1833, 27, 394-397.

[89] R. Clausius, Ann. Phys. Chem. (Poggendorff ed.) 1857, 101, 338-360.

[90] R. Clausius, Phil. Mag. 1858, 15, 94-109.

[91] R. Clausius, Ann. Chim. Phys. 1858, 53, 252-256.

[92] O. Markovitch, H. Chen, S. Izvekov, F. Paesani, G. A. Voth, N. Agmon, J. Phys. Chem. B 2008, 112, 9456-9466.

[93] F. Bagnoli, R. Livi, Substantia 2018, 2, 121-134.

[94] M. Faraday, J. Sci. Arts 1816, 1, 261-262.

[95] M. Faraday, Phil. Trans. 1821, 111, 47-74.

[96] M. Faraday, Quart. J. Sci. 1823, 15, 71-74.

[97] M. Faraday, H. Davy, Phil. Trans. 1823, 113, 160-165.

[98] M. Faraday, Phil.Trans. 1825, 115, 440-466. 
[99] J. C. Oersted, Ann. Phil. 1820, 16, 273-276.

[100] M. Faraday, Quart. J. Sci. 1822, 12, 74-96.

[101] M. Faraday, Quart. J. Sci. 1825, 19, 338.

[102] M. Faraday, Phil. Trans. 1832, 122, 163-194.

[103] M. Faraday, Phil. Trans. 1833, 123, 23-54.

[104] M. Faraday, Phil. Trans. 1833, 123, 507-522.

[105] M. Faraday, Phil. Trans. 1833, 123, 675-710.

[106] M. Faraday, Phil. Trans. 1834, 124, 55-76.

[107] M. Faraday, Phil. Trans. 1834, 124, 425-470.

[108] M. Faraday, Ann. Phys. Chem. (Poggendorff ed.) 1834, 31, 225-245.

[109] M. Faraday, Ann. Phys. Chem. (Poggendorf ed.) 1834, 32, 401-453.

[110] J. J. Berzelius, Jahres-Bericht über die Fortschritte der physischen Wissenschaften, Vol. 15. Jahrgang, Heinrich Laupp, Tübingen, 1836.

[111] F. A. J. L. James, The Correspondence of Michael Faraday, Institution of Electrical Engineers, London, 1991-2010.

[112] T. Martin, Being the Various Philosophical Notes of Experimental Investigation Made by Michael Faraday During the Years 1820-1862 and Bequeathed by Him to the Royal Institution of Great Britain, Vol. 1-7, George Bell \& Sons, London, 1932-1936.

[113] P. L. Simon, Ann. Phys. (Gilbert ed.) 1808, 28, 277 298.

[114] M. Faraday, Phil. Trans. 1846, 136, 1-20.

[115] M. Faraday, Phil. Trans. 1838, 128, 125-168. 